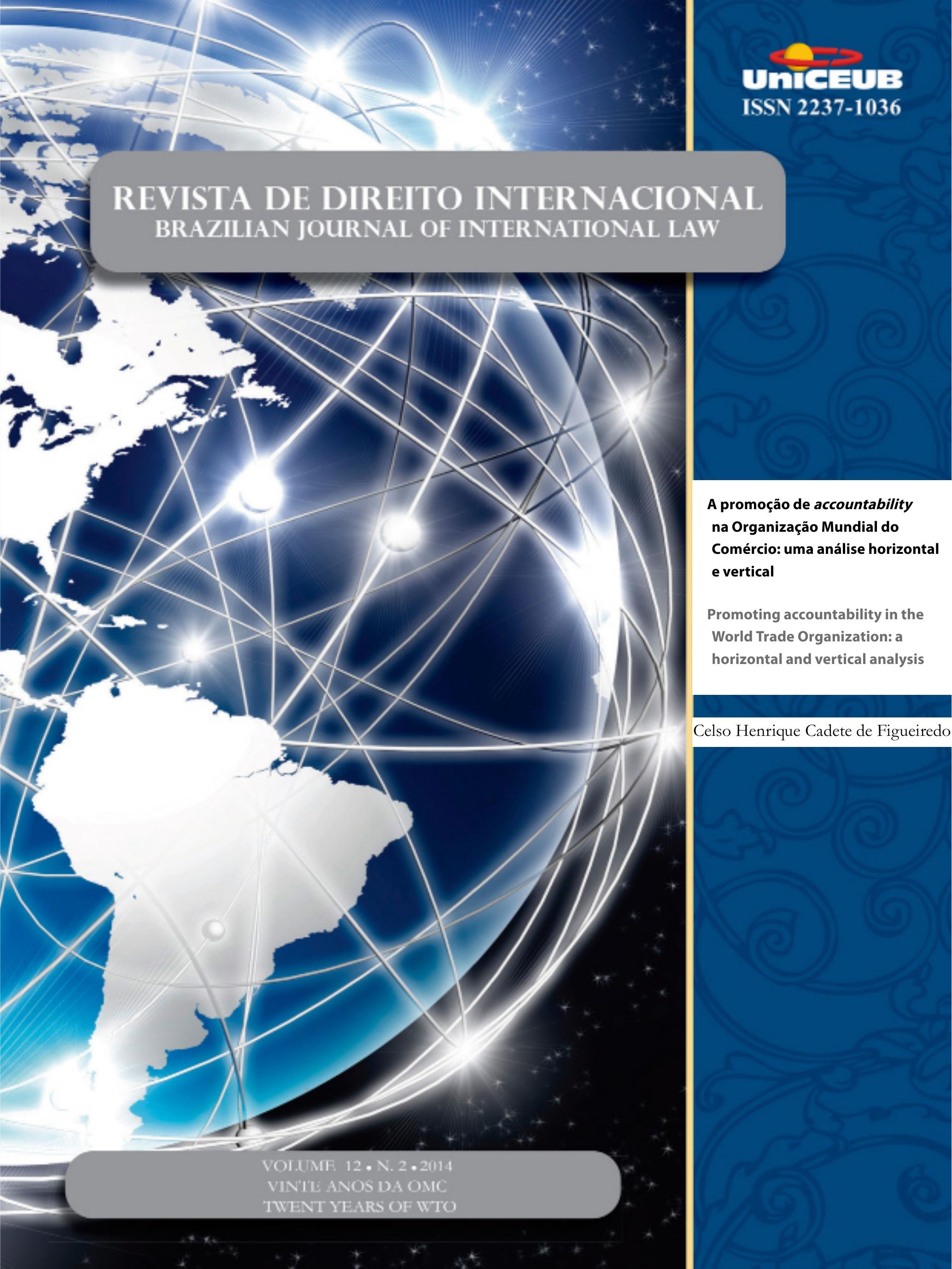


I. Crônicas

1. Crônicas da atualidade do Direito Internacional ......................................................16

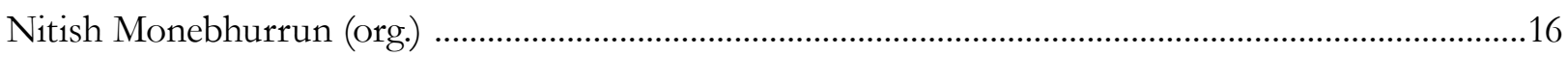

2.Decisões da Corte Internacional de Justiça e do Tribunal Internacional Sobre o Direito do Mar

Nitish Monebhurrun

José Eduardo Siqueira

3. Crônicas do direito internacional dos inVestimentos

Nitish Monebhurrun

\section{Os Vinte Anos dA OMC}

EXPORT CONTROLS AS INDUSTRIAL POLICY ON NATURAL RESOURCES: REGULATORY LIMITATIONS ON CHINA - RAW MATERIALS AND CHINA - RARE EARTHS CASES.

Gustavo Ferreira Ribeiro

O problema da espionagem econômica internacional: Seria a Organização Mundial do CoMÉRCIO O FORO ADEQUADO PARA SUA APRECIAÇÃO?

Humberto A.Vasconcelos Lima

Naiana Magrini Rodrigues Cunha

International Standards for Intellectual Property Rights Protection: a reflection on CLIMATE-FRIENDLY TECHNOLOGY TRANSFER.

Guihong Zhang

Jiani Jiang

Can Wang

Os vinte anos da OMC, suas conquistas e desafios: uma análise do Brasil e o Sistema de SoLUÇõES DE CONTROvÉRsias

Etiene M. Bosco Breviglieri

Luciano Meneguetti Pereira

A relação entre os tratados multilaterais ambientais e os acordos da OMC: é possível CONCILIAR O CONFLITO?

Fabio Costa Morosini,

Luisa Zuardi Niencheski 
Um desafio na Organização Mundial do Comércio: viabilidade de um aCordo plurilateral SOBRE ENERGIA

Matheus Linck Bassani

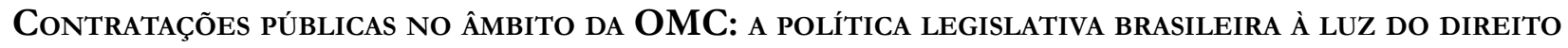
AO DESENVOLVIMENTO

André Jansen do Nascimento

Governança global e a Organização Mundial do Comércio: desafios impostos pelo novo MANDATO DE DESENVOLVIMENTO

Letícia de Souza Daibert

Ana Luísa Soares Peres

Vinte Anos de Crise para a África? Poder, Assimetrias e a Abordagem liberal da OMC.....239 Igor Abdalla Medina de Souza

Os MECANISMOS DE INDUÇÃo AO CUMPRIMENTO NO ÂMBITO DA OMC.

Fernando Lopes Ferraz Elias

A promoção de accountability na Organização Mundial do Comércio: uma análise horiZONTAL E VERTICAL

Celso Henrique Cadete de Figueiredo

LA OMC Y EL PROCESO DE GLOBALIZACION DE LA REGULACIÓN ALIMENTARIA

Maria Eugenia Marichal

O ACORDO GATS E SUA APLICAÇÃo AOS SERVIÇOS DO COMÉRCIO ELETRÔNICO

Gleisse Ribeiro Alves

A OMC E o REgionalismo do SÉculo XXI: ESTRATÉGIA DE IMPOSIÇão DE MODELOS NORMATIVOS? .. 337 Camilla Capucio

A organizaÇão mundial do Comércio e a China: direito de Propriedade e Propriedade inteLECTUAL NO PAÍ́S

Dos contenciosos NA OMC COM ENFOQue EM RESTRIÇões Às EXPORTAÇõEs dA China .363

Marco Antônio Alcântara Nascimento 
Alice Rocha da Silva

\section{Outros Temas}

Derechos Humanos en la ReAlidad aCtual: LA GLOBAlización y El MUlticulturalismo.

David Falcão

IMUNIDAdE DE JURISDIÇÃo do EsTAdo E REPARAÇÃo CIVIL PELA PRÁtiCA DE TORTURA: O CASO ZaHRA

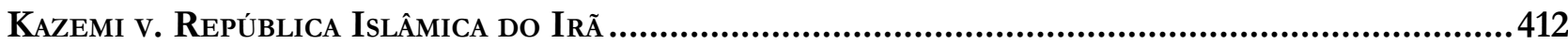

Patrícia Maria Lara Abreu

Rodrigo Otávio Bastos Silva Raposo

INTERREGIONAL ORGANIZATIONS (IROS) IN EUROPE: NEW SUBJECTS OF CONTEMPORARY INTERNA-

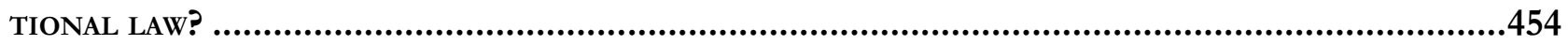

Davorin Lapas

A Conexão entre os direitos humanos e a Corrupção.

Gabriela Alves Mendes Vieira

Marcelo Dias Varella

GRUPO DE SOCIEDADES: INSTRUMENTO JURÍDICO DE ORGANIZAÇÃo DA EMPRESA PLURISSOCIETÁRIA.....495

Daniel Amin Ferraz 


\title{
A promoção de accountability na Organização Mundial do Comércio: uma análise horizontal e vertical*
}

\author{
Promoting accountability in the World Trade \\ Organization: a horizontal and vertical analysis
}

Celso Henrique Cadete de Figueiredo**

\section{Resumo}

O objetivo deste artigo é investigar se, na atual governança global, a Organização Mundial do Comércio (OMC) consegue promover accountability no seu âmbito de atuação. Primeiramente, serão apresentados conceitos e elementos básicos de accountability e expostas as dificuldades de transplantá-los diretamente para o âmbito global, vez que não existe uma sociedade global definida. Posteriormente, sob duas linhas teóricas, a intergovernamental e a supranacional, serão definidos os atores aos quais a OMC pode promover accountability $3 / 4$ respectivamente, os países membros e a sociedade civil organizada. Nessas linhas, será avaliada se no âmbito interno da OMC é possível identificar a presença de três elementos chaves da accountability $3 / 4$ padrões, informações e sanções $3 / 4$ tanto numa perspectiva horizontal de accountability, isto é, entre os próprios países membros, ou sob uma perspectiva vertical, com a OMC e os países membros em uma ponta e a sociedade civil em outra. Tal análise leva a conclusão de que se encontram satisfatoriamente todos os elementos de accountability numa perspectiva horizontal, porém, verticalmente não se pode afirmar que a OMC consiga promover accountability. A pesquisa teve que limitar tanto a abrangência do termo accountability a um contexto que possibilitasse a atual análise, como o escopo de sociedade civil particularmente às ONGs devido à própria prática da OMC de considerá-las representações sociais mais aptas de participação. Por fim, a originalidade deste trabalho tem o intuito de reforçar o diálogo em volta de sugestões para promover accountability verticalmente, e consequentemente debater a legitimidade da OMC.

* Recebido em 30.10 .2014

Aceito em 10.12.2014

** Mestre em Direito Econômico pela Universidade Federal da Paraíba. Especialista em Direito Tributário pela Universidade Paulista. Graduado em Direito pela Universidade Federal da Paraíba. Graduado em Relações Internacionais pela Universidade Estadual da Paraíba. Atualmente é Consultor Jurídico em Comercio Internacional pela GO Associados. henriquecadete@yahoo.com.br
Palavras-chave: OMC. Governança Global. Accountability. Países membros. ONGs.

\section{Abstract}

The aim of this paper is to investigate whether, in the current global governance, the World Trade Organization (WTO) can promote accountability within its operations. First, it will be presented basic concepts and elements of accountability and then it will be exposed the difficulties of transplanting them directly into the global context, since there is no defined global society. Subsequently under two theoretical lines, intergovernmental and supranational, the actors of which the WTO can promote accountability will be defined respectively the member states and civil society organizations. Under these lines it will be evaluated within WTO whether is possible to identify the presence of three key elements of accountability - standards, information and penalties 
- both a horizontal perspective of accountability, that is, between the member countries themselves, or from the perspective vertical, between WTO member countries on a point and civil society on another. Such analysis leads to the conclusion that all the elements of accountability in a horizontal perspective are satisfactorily meet, however, vertically one cannot say that the WTO promotes accountability. The research had to limit both the term accountability to a context that enabled the current analysis, and the scope of civil society, particularly to NGOs, due to the practice of the WTO to consider them more apt to participate as social representations. Finally, the originality of this work aims to enhance dialogue around suggestions for promoting accountability vertically, and therefore debate the legitimacy of the WTO.

Keywords: WTO. Global Governance. Accountability. Member Countries. NGOs.

\section{Introdução}

A Organização Mundial do Comércio (OMC), criada em 1995, evoluiu e se fortaleceu ao longo desses vinte anos em paralelo às mudanças na forma pela qual a governança global ${ }^{1}$ em si é ordenada. De forma resumida, a atual governança global pode ser identificada como um complexo de regras e instituições

1 Uma das conceituações mais famosas tentando traduzir as mudanças correntes nas interações políticas, sociais e jurídicas no mundo atual foi emitida pela Comissão sobre a Governança Global que tentou reconceitualizar a governança global da seguinte forma: "[...] a soma das várias maneiras em que os indivíduos e instituições, pública e privada, gerenciam seus interesses comuns. É um contínuo processo através dos quais conflitos ou interesses diversos podem ser acomodados e, ações cooperativas podem ser tomadas. Incluem-se instituições formais e regimes autorizados para aplicar a observância, tanto quanto arranjos informais na qual pessoas e instituições também tenham acordado para, ou entendidas como sendo do seu interesse. [...] A nível global, governança vem sendo vista primariamente como relações intergovernamentais, mas deve ser entendida agora como também por envolver organizações não governamentais (ONGs), movimentos de cidadãos, corporações multinacionais e o mercado de capital global [...] não existe um simples modelo ou forma de governança global, nem existe uma singular estrutura ou um conjunto de estruturas. É um processo complexo, dinâmico e amplo de interativas tomadas de decisões que está constantemente evoluindo e respondendo as circunstâncias mutatórias". Em: COMISSÃO SOBRE GOVERNANÇA GLOBAL. Nossa Comunidade Global: o relatório da Comissão sobre Governança Global. Rio de Janeiro: Editora FGV, 1996, p. 4. regulatórias que se aplicam a jurisdições transnacionais e constituições sociais ${ }^{2}$.

De forma mais profunda, a atual governança global, vai além da governança produzida pelas Organizações Internacionais (OIs), uma vez que estas são entendidas em termos de relações entre Estados Nações, envolvendo, portanto outros tipos de atores tais como empresas, associações da sociedade civil, governos locais e agências regulatórias ${ }^{3}$.

A priori desenhada para atuar como uma Organização Internacional Intergovernamental que funcionasse nos moldes de uma arena de produção de regras, na qual os países membros teriam a oportunidade de negociar os acordos comerciais que regeriam as suas relações comerciais e, também como uma agência administrativa para cuidar da adequação e aplicação dessas regras ${ }^{4}$, a OMC testemunhou o crescimento do interesse de atores não estatais e, sua atuação, em virtude, por exemplo, da regulamentação de temas de interesse público, tais como a proteção ao meio ambiente, a saúde humana e animal.

De forma mais clara, é possível encontrar na própria aplicação de alguns padrões regulatórios estabelecidos pela OMC $3 / 4$ tais como padrões fitossanitários contidos no Acordo de Medidas Sanitárias e Fitossanitárias $(\mathrm{SPS})^{5} 3 / 4$ a atuação de algumas organizações híbridas ${ }^{6}$, como por exemplo, a Codex Alimentarius, ou por vezes privadas, tal como a International Standartization

2 SCHOLTE, Jan Aart. Global governance, accountability and civil society. In: SCHOLTE, Jan Aart (Ed.). Building global democracy: civil society and global governance. Cambridge: Cambridge University Press, 2011.

3 SCHOLTE, Jan Aart. Global governance, accountability and civil society. In: SCHOLTE, Jan Aart (Ed.). Building global democracy: civil society and global governance. Cambridge: Cambridge University Press, 2011. p. 10.

4 CHARNOVITZ, Steve. Transparency and participation in the World Trade Organization. GWU Law School Public Law Research Paper, Washington, n. 142, 2004. p. 16-21.

5 No caso do SPS tal relação fica mais palpável, uma vez que no anexo A do acordo está institucionalizada a adoção de padrões providos pelas "três irmãs" (Codex Alimentarius, Escritório Internacional de Epizootias, e Convenção Internacional sobre Proteção Vegetal.

6 Que mantém uma Administração híbrida intergovernamental-privada, sendo entendidos como órgãos que combinam atores privados e governamentais e assumem formas diferentes e cada vez mais relevantes. KINGSBURY, Benedict; KRISCH, Nico; STEWART, Richard B. The emergence of global administrative law. Law and Contemporany Problems. North Carolina, v. 68, n. 3-4, p. 15-62, 2005. 
Organization (ISO) $3 / 4$ que estabelece padrões de qualidades por vezes adotados para solução de disputas concernentes ao Acordo de Barreiras Técnicas (TBT).

Dessa forma, resta cada vez mais claro que o processo de tomada de decisões, administração e aplicação de medidas na OMC acaba envolvendo uma série de atores estatais e mesmo não estatais, dentro de uma variedade de mecanismos, que não se conformam em uma noção tradicional de governança intergovernamental onde apenas os países membros teriam voz?

Por fim, uma vez que as regras estabelecidas no âmbito da OMC perpassam a esfera internacional e atingem a legislação doméstica de vários países, e concorrentemente a vida das pessoas de forma direta, resta difícil negar a amplitude de interesses que possam permear a atuação da OMC.

É, portanto, no ínterim desse amplo debate sobre a governança global que passou-se a discutir a existência ou a necessidade de criação de ferramentas que promovam accountability, como forma de garantia de legitimidade das organizações internacionais, em particular a OMC, para com os seus membros, mas também para aqueles atores não estatais que integram este novo sentido de governança.

As demandas por accountability dentro da OMC partem, principalmente, de dois setores, dos países em desenvolvimento, ávidos por manter uma maior influência na organização com vistas a terem consideradas as suas agendas e, a sociedade civil, em especial as ONGs, que demandam um canal que possa manter os rumos da organização atrelados ao interesse público global ${ }^{8}$.

Uma vez que a accountability é vista por ter um papel central de legitimidade no atual contexto de governança global no qual se encontram presentes uma variedade de atores interessados, que não apenas os países membros, o presente trabalho pautou seu objetivo principal na seguinte questão: a OMC promove accountability?

Porém, responder a pergunta a respeito de a OMC promover accountability, perpassa primeiramente por definir o que se entende por accountability na perspectiva da atual governança global e, em segundo lugar, para

7 MITCHELL, Andrew D.; SHEARGOLD, Elizabeth. Global governance: the World Trade Organization's contribution. Alberta Law Review, Alberta, v. 46, p. 1061-1080, jan. 2010.

8 CHARNOVITZ, Steve. Transparency and participation in the World Trade Organization. GWU Law School Public Law Research Paper, Washington, n. 142, 2004. quem a OMC deve promover accountability e, de que forma se está, ou não, sendo accountable. É com base nesse desafio que estão estabelecidos os objetivos específicos do presente trabalho: primeiramente perseguir um entendimento do termo accountability na perspectiva da governança global, em segundo lugar, investigar de que forma esse parâmetro pode ser aplicado no âmbito da OMC, ou seja, identificando os potenciais account holders, para enfim fazer uma análise e promover uma reflexão acerca da questão da accountability no âmbito da OMC

Nesse sentido, o presente trabalho foi dividido em quatro seções (sendo a primeira seção a própria introdução) a segunda seção será destinada a introduzir o leitor ao conceito de accountability $3 / 4$ este primeiramente designado para explicar uma relação de poder e legitimidade constante no ambiente político doméstico $3 / 4$ que correntemente é bastante invocado em debates sobre governança global, quando se questiona a adoção de processos ou mecanismos de accountability para avaliar a legitimidade da atuação de Organizações Internacionais. Nesta seção o leitor entenderá os três elementos chave do processo de accountability (padrões, informação e sanção), e de que forma a interação destes três elementos formam o processo ou criam mecanismos de accountability.

$\mathrm{Na}$ terceira seção, se debruçará especificamente para quem a OMC deve ser accountable, uma vez que se fazem presentes duas vertentes que defendem posições distintas sobre tal questão, uma abordagem intergovernamentalista, que enxerga apenas os países membros como detentores do direito de manter as regras da OMC accountable, e uma abordagem supranacionalista que enxerga na sociedade civil o destinatário final das normas da OMC e por isso entendem que estes são os detentores do direito de manter a OMC, e em ultima instancia os países membros, accountable.

$\mathrm{Na}$ quarta seção será analisada a existência de elementos chave de accountability dentro de uma perspectiva intergovernamental da OMC, partindose do pressuposto que os detentores de poder e os encarregados de cumprir as normas da OMC são os próprios países membros, em uma relação de poder horizontal. Dessa forma, serão verificados quais institutos e ferramentas institucionais dentro da OMC permitem aos membros estabelecerem padrões, se informarem sobre o cumprimento das normas pelos outros países e, por fim, estabelecerem sanções em caso de descumprimento. 
$\mathrm{Na}$ quinta seção, será analisada a existência de elementos chave de accountability dentro de uma perspectiva supranacional, estabelecendo-se a sociedade civil organizada, em particular ONGs, como destinatária final das normas da OMC e, desta forma, dentro de uma relação vertical. Da mesma forma, serão verificados institutos e ferramentas institucionais dentro da OMC que permitam à sociedade civil utilizar dos três elementos chave da accountability.

Por fim, serão feitas as considerações finais que, ressaltadas as dificuldades metodológicas (como, por exemplo, definir accountability e sociedade civil) e algumas limitações do objeto a ser perseguido, firmarão algumas impressões do presente estudo. Em primeiro lugar reconhecendo que, embora não seja utilizada de forma igual por todos os países membros, a OMC, em uma perspectiva horizontal, fornece de forma satisfatória os três elementos chave na promoção de accountability. Porém, apesar de tentar estreitar os vínculos com a sociedade civil organizada, no que diz respeito a disponibilização de ferramentas de formulação de regras e estabelecimento de sanções, a sociedade civil não encontra espaço para tornar a OMC, e ultimamente, os seus países membros, accountable.

O desenvolvimento do presente trabalho se deu com base em uma considerável pesquisa bibliográfica, que se fundamentou, em referenciais teóricos, tanto da governança global, como de accountability e OMC. Para tanto, além da doutrina sedimentada em obras físicas, como livros e revistas, foram utilizadas bases bibliográficas de portais como o Institute for International Law and Justice, Social Science Research Network, Jstor e Scielo, assim como as publicações e documentos oficiais contidos na base de dados disponibilizados pelo site da OMC.

A relevância da pesquisa reside no desbravamento de um tema atual, qual seja, accountability na governança global. Nesse aspecto, toma-se o enfoque da promoção de accountability em uma das Organizações Internacionais mais importantes do mundo, a OMC. Portanto, através do presente trabalho, espera-se fortalecer a gama de trabalhos sobre governança global e OMC.

\section{As dificuldades da aplicação da accountability na governança global}

Accountability é um termo originalmente designado para descrever uma relação de poder entre dois entes num ambiente doméstico, no qual um detentor de poder deve prestar contas das suas ações aos administrados de forma a evitar abusos de poder ou mesmo déficits de legitimidade.

Embora o termo accountability tenha sido pensado primeiramente ligado à ideia de responsabilidade, posteriormente passou a ser utilizado como um conceito a parte, não obstante a manutenção do grande peso que a responsabilidade tem para a accountability em termos de importância e escopo?.

A partir da década de 80 , com as reformas do New Public Management, o termo accountability passou a ter utilização mais ampla, e o seu estudo passou a ser abordado pelo direito administrativo, relações internacionais e pela administração tanto do setor público, como também em corporações provadas e mesmo no mercado financeiro.

De forma geral accountability pode ser entendido como uma relação específica ou um mecanismo que envolva a obrigação de explicar e justificar uma conduta, ou, na concepção de "a process of being called to account to some authority for one's actions" ${ }^{10}$. Isto implica na relação entre um accountee, ou mesmo agente, de um lado, e, de um fórum, account holder, accountor, ou principal do outro lado, onde o primeiro ator deve justificar e prestar conta das suas condutas ao segundo. Em outras palavras, o accountee é aquele agente ao qual foi transferida a incumbência de agir em nome de outrem, ou subordinado a outrem, ou mesmo em nome de determinada regra estabelecida por terceiros. Estes terceiros seriam os detentores do poder de cobrar que a conduta do accountee esteja de acordo com aquilo que havia sido estabelecido, os detentores de poder seriam, assim, account holders.

9 MULGAN, Richard. One cheer for hierarchly: accountability in disjointed governance. Political Science, v. 55 n. 2, p.6-18, 2003.

10 MULGAN, Richard. One cheer for hierarchly: accountability in disjointed governance. Political Science, v. 55, n. 2, p.6-18, 2003. p. 555. 


\section{TABELA 1 - Atores componentes da relação de accountability}

Ator que detém o poder de agir representando outrem sob o respeito de padrões/normas previamente estabelecidas:

\begin{tabular}{|l|l|}
\hline Accountee & Account bolder/Accountor \\
\hline Detentor de Poder/Delegado & Constituinte/Fórum/ Outorgante \\
\hline Agente & Principal \\
\hline
\end{tabular}

Fonte: Formatação própria

Apesar de diversos autores enfatizarem vários modelos de accountability, tais como, a accountability hierárquica ${ }^{11}$, a accountability legal ${ }^{12}$, a accountability política ${ }^{13}$ e a accountability profissional $^{14} 3 / 4$ sendo cada um desenhado para refletir uma fonte maior e legítima de expectativas para o comportamento administrativo e as diferentes relações dentro de um ambiente democrático $3 / 4$ de forma geral vislumbra-se em todos esses modelos de accountability três elementos chaves que tornam tais mecanismos susceptíveis

11 As relações de accountability hierárquica são aquelas amplamente aceitas pelo público em geral uma vez que se baseia em critérios de supervisão apurada e conjunto com o cumprimento com diretivas. Em: DUBNICK, Melvin J.; ROMZEK, Barbara. Accountability. In: SHAFRITZ, Jay M. (Org.). The International Encyclopedia of Public Policy and Administration. Westview Press, 1998. v. 1.

12 As relações accountability legal emergem de uma arena onde as autoridades têm a expectativa que os agentes oficiais tomem conta das suas atividades de acordo com as obrigações legais, constitucionais, contratuais e mesmo principiais. In: DUBNICK, Melvin J.; ROMZEK, Barbara. Accountability. In: SHAFRITZ, Jay M. (Org.). The International Encyclopedia of Public Policy and Administration. Westview Press, 1998. v. 1.

13 As relações de accountability observa-se na relação entre os oficiais eleitos e os seus constituintes eleitores como uma relação de accountability política que preza pela responsividade, uma vez que não sendo responsivos, os oficiais eleitos se tornam de forma crescente insusceptíveis de serem mantidos ou reeleitos no cargo. Em: DUBNICK, Melvin J.; ROMZEK, Barbara. Accountability. In: SHAFRITZ, Jay M. (Org.). The International Encyclopedia of Public Policy and Administration. Westview Press, 1998. v. 1.

14 As relações de accountability profissional se desenvolvem em ambientes de trabalho, onde se enxerga a responsabilidade de um administrador em manter a sua discrição, conduta e desempenho de uma maneira compatível com as melhores práticas profissionais. Em: DUBNICK, Melvin J.; ROMZEK, Barbara. Accountability. In: SHAFRITZ, Jay M. (Org.). The International Encyclopedia of Public Policy and Administration. Westview Press, 1998. v. 1.
Ator que é representado e tem o direito de manter accountable aquele que o representa através de processos de transparência/consultas, com a possibilidade de aplicação de sanções:

Constituinte/Fórum/ Outorgante

de serem efetivos. São eles: padrões (Standards), informação (information) e, sanção (sanction) ${ }^{15}$.

Essa estrutura tridimensional é bastante reproduzida ${ }^{16}$, de forma que, basicamente, o processo de accountability pressupõe um relacionamento entre os encarregados do poder e aqueles que os mantém accountable, num cenário onde se verifica a existência de um reconhecimento geral de legitimidade dos padrões operacionais para accountability e da autoridade das partes para o relacionamento, ou seja, um exercendo o poder particular e o outro tentando manter o primeiro accountable ${ }^{17}$.

Esses elementos formam um processo constituído de quatro fases, em que a primeira fase cuida de estabelecer quais os padrões os detentores de poder ou accountees devem seguir. O estabelecimento de tais padrões (normas, regras, procedimentos, etc.) pode ser feito de forma conjunta entre os account holders e os detentores de poder, ou somente pelos account holders sendo reconhecidos posteriormente pelos accountees.

$\mathrm{Na}$ segunda fase, os account bolders adquirem informações sobre o cumprimento, ou não, dos padrões estabelecidos. Nesse sentido, os detentores de poder devem explicar que: (a) eles cumpriram com os padrões; (b) que eles não cumpriram, mas por uma justificativa compreendida nos padrões; (c) que eles de

15 RUBENSTEIN, Jennifer. Accountability in an unequal world. Journal of Politics, v. 69, n. 3, p. 616-632, ago. 2007.

16 Tal definição também é utilizada por: STEWART, Richard B. Accountability and the discontents of globalization: US and EU models for regulatory governance. In: University Hauser Colloquium on Globalization and its Discontents, Discussion Draft, Nova Iorque, 2006; e, DYZENHAUS, David. Accountability and the concept of (global) administrative law. IILJ Working Paper, Nova Iorque, n. 7, 2008.

17 GRANT, Ruth W.; KEOHANE, Robert O. Accountability and abuses of power in world politics. American Political Science Review, v. 99, n. 1, fev. 2005. 
forma injustificada não cumpriram, mas existe uma desculpa para tal descumprimento, ou; (d) que eles não cumpriram e falta uma justificação, assim como uma desculpa para tanto ${ }^{18}$.

Destarte, com base na informação adquirida, uma decisão é tomada acerca da implementação, ou não, de uma sanção ao detentor de poder. É este componente repressivo do processo que dá dentes à accountability, e, assim, distingue-o de responsabilidade, que, em resumo é capacidade de resposta e deliberação ${ }^{19}$. Portanto, o propósito da fase de sanção é pressionar o detentor de poder a cumprir com os padrões relevantes e, para a sanção servir a este propósito, o detentor de poder deve estar a par tanto dos padrões como do potencial da sanção que lhe possa atingir.

A quarta e última fase acontece quando os padrões aos quais os accountees (detentores de poder de agir) estão atrelados mudam com o tempo. Claro que tais mudanças podem sofrer resistência por parte dos accountees, fato pelo qual pode incorrer em desfechos distintos dependendo da força de imposição do constituinte/account holder, podendo a regra ser imposta, ser aberto um processo de negociação entre as partes, ou mesmo de substituição dos accountees $^{20}$. De forma esquematizada podemos visualizar o processo de accountability da seguinte forma:
Em resumo, para se haver accountability, é necessária a presença de regras ou padrões a serem seguidos, um canal que permita a informação do cumprimento ou não dos padrões por aqueles que detém o poder ou o dever de administrar e, por último, a possibilidade de punir os account holders quando não verificado o cumprimento dos padrões ou quando detectado abuso de poder por parte deste.

Dentro de um ambiente doméstico, é possível enxergar quais os tipos de accountability que se desenvolvem e quais são os atores dessa relação. Neste sentido, Ruth W. Grant e Robert O. Keohane construíram uma matriz que parece descrever bem quais tipos de accountability se desenvolvem dentro de um ambiente doméstico democrático. Tal relação pode se dividir em dois conceitos básicos: accountability por delegação e accountability por participação. A diferença entre os dois modelos se encontra basicamente na resposta à seguinte pergunta: "Quem é intitulado a manter o poder accountable?". Enquanto no modelo de participação o desempenho dos detentores de poder (agentes) é avaliado por aqueles que são afetados pelas suas ações (principais), no modelo de delegação o desempenho é avaliado por aqueles que confiaram o poder a terceiros (outorgantes) ${ }^{21}$.

\section{FIGURA 1 - Fases do processo de accountability}

\begin{tabular}{|l|l|l|l|l|}
\hline $\begin{array}{l}\text { 1. Os account holders } \\
\text { criam e os detentores de } \\
\text { poder reconhecem os } \\
\text { padrões. }\end{array}$ & $\begin{array}{l}\text { 2. Os account holders recebem } \\
\text { informações sobre } \\
\text { cumprimento detentores de } \\
\text { poder em relação aos padrões. }\end{array}$ & $\begin{array}{l}\text { 3. Os account holders } \\
\text { aplicam, ou não as } \\
\text { sanções nos detentores } \\
\text { de poder. }\end{array}$ \\
\hline
\end{tabular}

Fonte: RUBENSTEIN, Jennifer. Accountability in an unequal world. Journal of Politics, v. 69, n. 3, p. 616-632, ago. 2007. p. 618.

18 RUBENSTEIN, Jennifer. Accountability in an unequal world. Journal of Politics, v. 69, n. 3, p. 616-632, ago. 2007.

19 RUBENSTEIN, Jennifer. Accountability in an unequal world. Journal of Politics, v. 69, n. 3, p. 616-632, ago. 2007. p. 619.

20 RUBENSTEIN, Jennifer. Accountability in an unequal world. Journal of Politics, v. 69, n. 3, p. 616-632, ago. 2007. p. 619620.
Percebe-se, portanto, que em um contexto doméstico democrático, os mecanismos de accountability quaisquer eles que sejam, acabam se tornando ferramentas de controle de poder e, consequentemente, acabam se tornando um filtro de legitimidade, onde aqueles detentores de poder que são accountable são legítimos aos olhos dos account holders.

21 GRANT, Ruth W.; KEOHANE, Robert O. Accountability and abuses of power in world politics. American Political Science Review, v. 99, n. 1, fev. 2005. 
No entanto, quando tais concepções de accountability são transpostas para um cenário de governança global, na tentativa de analisar para quem a OMC deve ser accountable, resta intangível uma resposta exata.

Isto porque ao contrário de antigamente onde o debate se simplificava na lógica do sistema internacional westfaliano, somente os Estados deveriam ter obrigações de accountability uns aos outros de forma horizontal, e verticalmente com relação às Organizações Internacionais, o atual cenário de governança global convergiu para uma multiplicidade de atores não estatais que tanto passaram a ocupar posições reguladoras e administrativas, como também se inserirem na posição de regulado.

Tal debate é, hoje, de fundamental importância na academia, uma vez que a legitimidade de vários atores internacionais, e em particular a OMC, é questionada diante da caracterização de déficits democráticos, uma vez que as elites políticas internacionais, mormente não são formadas de representantes eleitos pelo povo e, segundo, não existe uma identidade coletiva compartilhada e nem uma cultura de suporte comum às instituições internacionais ${ }^{22}$.

E, quando se analisa o destinatário final das normas e tomadas de decisões permeadas no âmbito global, percebe-se que, na maioria das vezes, o indivíduo ou a sociedade como um todo são atingidas, ou seja, sofrem o impacto das normas. É nesse sentido que, nos últimos anos, vem crescendo a demanda tanto por parte da academia, como por parte das organizações da sociedade civil organizada, e mesmo de indivíduos, para o estabelecimento de critérios capazes de amenizar o asseverado déficit de legitimidade oriundo da falta de um adequado ambiente democrático a nível global, em especial, mecanismos de accountability. Legitimidade aqui entendida no sentido normativo de se ter o direito de regular. No contexto internacional, a legitimidade se apresenta conceituada tanto de forma relacional, uma vez que é construída por relações dialéticas entre organizações globais e atores externos, e, por relações contestadas, tendo em vista que diferentes atores irão desacordar sobre o que se requere para que uma organização global seja legítima ${ }^{23}$.

22 NANZ, Patricia; STEFFEK, Jens. Global governance, participation and the public sphere. In: HELD, David; KOENIG-ARCHIBUGI, Matias. (Ed.). Global governance and public accountability. Chichester: Wiley-Blackwell, 2005, p. 190-211.

23 PEDRAZA-FARINA, Laura G. Conceptions of civil society in international law-making and implementation: a
Em termos gerais, é possível vislumbrar dois tipos de accountability na governança global, a accountability interna, que seria aquela que envolve controle por parte dos constituintes que tem o poder de autorização ou de suporte, e a accountability externa, considerada como mecanismos que privilegiam pessoas de fora da entidade atuante as quais as vidas são afetadas ${ }^{24}$.

No entanto, a partir do momento em que se torna impossível caracterizar uma sociedade pública global uníssona, que possa ser constituída como account holder da governança global, cria-se um déficit de legitimidade das tomadas de decisões e regulações adotadas globalmente, uma vez que estas não perpassaram por uma escolha democrática e não encontram mecanismos de accountability para restringir abusos de poder.

Diante da referida ausência de uma demos global, uma figura vem se tornando bastante popular, como forma de se tentar preencher a lacuna de accountability externa gerada pela maioria das organizações multilaterais globais e mesmo atividades de organismos globais híbridos e privados: a denominada sociedade civil.

Inclusive, no âmbito da OMC, esse debate é bastante acirrado, uma vez que restam argumentos sedimentados sobre para quem a OMC deve ser accountable, se para os países membros, ou mesmo para a sociedade civil, conforme será exposto na próxima seção.

\section{Para quem a OMC deve promover accountability?}

Segundo Marc Williams ${ }^{25}$, existem visões conflitantes sobre os atores aos quais a OMC deveria ser accountable ou promover accountability, tendo em vista que, argumentar sob perspectivas na qual a OMC encontra padrões contemporâneos de accountability constitui uma importante característica do relacionamento entre a OMC os seus membros e a sociedade civil. Dois grandes posicionamentos são discerníveis neste debate: um, que pode ser denominado de abordagem intergovernamental e, o outro, denominado abordagem supranacional.

theoretical framework. Michigan Journal of International Law, Michigan, v. 34, n. 3, p. 101-173, 2013.

24 KEOHANE, Robert O. Global governance and democratic accountability. In: HELD, David; KOENIGARCHIBUGI, Mathias (Eds.). Taming globalization: frontiers of governance. Cambridge: Polity Press: 2002.

25 WILLIAMS, Mark. Civil society and the WTO: contesting accountability. In: SCHOLTE, Jan Aart (Ed.). Building global democracy: civil society and global governance. Cambridge: Cambridge University Press, 2011. 
Os analistas, que adotam uma abordagem estritamente intergovernamental da OMC, negam qualquer requerimento para a OMC ser accountable a atores outros que governos nacionais. Eles argumentam que a OMC segue um club model governance, que, basicamente defende que, a legitimidade das organizações da governança global é inteiramente derivada da constituição formal dos seus membros, o que no caso da OMC se limita aos Estados. De acordo com essa perspectiva, os Estados se engajam na governança global sob a base de autoridade legítima delegada a eles pelos seus cidadãos, assim, qualquer verificação de accountability da governança global por parte dos cidadãos reside nos governos nacionais ${ }^{26}$.

A OMC basicamente pode ser enxergada uma agência administrativa na qual os países membros tomam as decisões chaves e inovam legalmente. Ela estaria limitada a supervisionar a ordem legal concebida pelos Estados. Vista por esse angulo, a OMC deve ser accountable aos seus membros, demandando, portanto, uma accountability exercida internamente ${ }^{27}$.

Marc Williams coloca que, de uma perspectiva intergovernamentalista, questões de accountability poderiam surgir de duas formas na OMC: em um primeiro sentido, um déficit de accountability pode emergir se os mecanismos institucionais evitam que algum Estado Membro colha os benefícios integrais da participação. Uma segunda forma de déficit de accountability pode surgir como resultado do impacto das políticas da OMC em populações específicas. (Ex. o caso do acesso a remédios para grandes populações carentes). Ainda assim, os intergovernamentalistas negam que os déficits de accountability devam requerer a intervenção da sociedade civil $^{28}$. A resposta, para eles, seria melhorar os procedimentos de tomadas de decisão dentro da OMC, para permitir maior equidade entre os Estados Membros.

Já os que enxergam a OMC como uma organização supranacional defendem que o impacto da atuação da

26 WILLIAMS, Mark. Civil society and the WTO: contesting accountability. In: SCHOLTE, Jan Aart (Ed.). Building global democracy: civil society and global governance. Cambridge: Cambridge University Press, 2011. p. 110.

27 KEOHANE, Robert O.; NYE, Joseph S. Power and interdependence. Boston: Scott, Foresman and Company, 2001.

28 WILLIAMS, Mark. Civil society and the WTO: contesting accountability. In: SCHOLTE, Jan Aart (Ed.). Building global democracy: civil society and global governance. Cambridge: Cambridge University Press, 2011. p. 111.
OMC na economia global transcende uma abordagem isoladamente intergovernamental e que, portanto, a OMC deveria promover accountability àqueles afetados pelas suas políticas. Eles se baseiam em três principais pontos: primeiro, a Rodada Uruguai, que resultou em uma significante transformação da forma pela qual se gerencia o comércio mundial. Em comparação com o GATT, o regime da OMC é muito mais extensivo (incluindo novos setores e novas questões, como propriedade intelectual e meio ambiente) e mais intrusivo em seu impacto em políticas, práticas e regulações domésticas ${ }^{29}$.

Em segundo lugar, clama-se que a OMC desenvolveu processos de supervisão, que redefiniram a forma pela qual se gerenciam o sistema comercial global, por meio do Mecanismo de Revisão de Política Comercial e o Mecanismo de Solução de Controvérsias que limitam a autoridade dos governos nacionais. Nesse ângulo, tem sido arguido que a OMC é um órgão administrativo supranacional emergente, uma vez que não é simplesmente mais um sistema baseado no consenso, reciprocidade e balanceamento de concessões, mas um sistema de regras que refletem na realidade do Estado $\operatorname{administrativo~}^{30}$.

Terceiro, a posição supranacional argumenta que o poder normativo da OMC efetivamente subverte a tomada de decisões políticas no âmbito nacional. A OMC incorpora uma série de compromissos específicos, facilita uma abertura do sistema de comércio global e uma desregulação das economias nacionais através da insistência de que os Estados removam as suas barreiras comerciais. Este processo pode, potencialmente, atropelar a legislação doméstica aprovada para preservar, por exemplo, valores culturais, recursos ambientais e padrões trabalhistas ${ }^{31}$.

Por isso, de acordo com uma perspectiva supranacionalista, todos os três processos dão base ao surgimento de déficits de accountability na OMC que

29 WILLIAMS, Mark. Civil society and the WTO: contesting accountability. In: SCHOLTE, Jan Aart (Ed.). Building global democracy: civil society and global governance. Cambridge: Cambridge University Press, 2011. p. 111.

30 WILLIAMS, Mark. Civil society and the WTO: contesting accountability. In: SCHOLTE, Jan Aart (Ed.). Building global democracy: civil society and global governance. Cambridge: Cambridge University Press, 2011. p. 112.

31 WILLIAMS, Mark. Civil society and the WTO: contesting accountability. In: SCHOLTE, Jan Aart (Ed.). Building global democracy: civil society and global governance. Cambridge: Cambridge University Press, 2011. p. 113. 
os Estados sozinhos não podem corrigir. Ademais, essas mudanças no regime de comércio global trazem a OMC em engajamento direto com grupo como consumidores, fazendeiros ou mesmo trabalhadores. Nessas bases, atores da sociedade civil poderiam ter um papel legítimo na governança da OMC e esta deveria ser accountable a sociedade civil da mesma forma que é para os Estados.

Com base no trabalho de Robert Wolfe é possível afirmar que uma visão intergovernamental leva ao exercício de uma accountability interna de dimensão horizontal onde os membros se mantêm accountable uns aos outros em um tipo de processo de revisão por pares. Ele entende que, os membros da OMC são muito mais confortáveis dentro de uma visão horizontal de accountability dada a sua crença profundamente interiorizada que a OMC é uma organização "memberdriven", portanto apenas aos próprios membros podem manter as regras da organização em voga e cobrar uns aos outros ${ }^{32}$.

Ao passo que, numa perspectiva supranacional, a OMC sendo accountable à sociedade civil se dá numa dimensão vertical, na qual as decisões tomadas no interior da organização $3 / 4$ seja pelos países membros, seja pela administração da OMC $3 / 4$ devem ser responsivas ao público afetado pela formulação de regras, padrões e tomadas de decisões estabelecidas em seu âmbito.

Restaria, portanto, saber de que forma se exerceriam as duas perspectivas (horizontal e vertical) de accountability, uma vez que a OMC não detém um órgão administrativo específico para manter os seus agentes accountable aos seus principais.

Tomando emprestado a leitura feita pelos professores Richard Stewart e Michelle Ratton Sanchez ${ }^{33}$, é possível identificar que em uma dimensão interna de atuação da OMC existe a presença de três componentes decisórios, sendo esses elementos básicos de accountability, quais sejam: a produção de regras e padrões originadas particularmente por meio de Conferências Ministeriais; o processo de informação e transparência com vistas a identificar a consonância das políticas e regras

32 WOLFE, Robert. Who is accountable at the World Trade Organization?: anatomy of a trilemma within a dilemma. Kingston, p. 1-19, (no prelo).

33 STEWART, Richard B.; SANCHEZ BADIN, Michelle Ratton. The World Trade Organization and global administrative law. NYU School of Law Public Law Research Paper, Nova Iorque, n. 09-71, p. 1-31, 2009. domésticas com os acordos multilaterais, em especial, por meio do Mecanismo de Revisão de Políticas Comerciais; e a possibilidade de aplicação de sanções em quando verificada a adoção de uma prática ou política comercial destoante com os padrões comerciais do sistema multilateral, através do Órgão de Solução de Controvérsias.

As próximas seções procurarão, assim, investigar se, dentro da dimensão interna de atuação da OMC, pode ser verificado o funcionamento dos três elementos fundamentais para a aplicação de mecanismos de accountability existentes ao nível global $3 / 4$ padrões, informações e sanções $3 / 4$ correlatos ao funcionamento dos componentes legislativo, administrativo e judiciário da OMC sob as dimensões, horizontal e vertical, de accountability e, neste sentido, tentar responder se na OMC se promove accountability.

\section{Elementos de accountability no plano horizontal}

A partir de uma visão intergovernamental da OMC, na qual esta deve ser accountable estritamente aos membros que a compõem e, partindo do artigo IX do Acordo Constitutivo da OMC, que estabelece a igualdade de seus membros, em função da regra de um país, um voto, o controle de abuso de poder dos seus membros tem que ser praticado de uma forma horizontal por meio de um processo de accountability de pares. Resta saber se a OMC fornece, de forma satisfatória, aos seus países membros os três elementos de consecução do processo de accountability, quais sejam: o estabelecimento de padrões, meios de supervisão do cumprimento dos padrões e possibilidade de sanção quando verificado o descumprimento.

\subsection{O componente legislativo como elemento de estabelecimento de padrões}

Conforme estatui o artigo VI:1 do Acordo que Constituiu a $\mathrm{OMC}^{34}$, o principal processo de criação de regras no âmbito desta se dá através das Conferências Ministeriais, que ocorrem, geralmente, a cada dois anos e, ao passo que a OMC se constitui uma organização

34 Acordo Constitutivo da Organização Mundial do Comércio. In: BRASIL. Decreto 1.355 de 30 de dezembro de 1994. Promulgo a Ata Final que Incorpora os Resultados da Rodada Uruguai de Negociações Comerciais Multilaterais do GATT. Presidência da República. Brasília, 30 dez. 1994. 
member-driven, demandam uma votação consensual para que novos acordos sejam estabelecidos.

Segundo Van den Bossche ${ }^{35}$, a Conferência Ministerial é o órgão supremo da OMC. É composto por representantes dos membros em grau de ministério e tem o poder de tomada de decisão sobre todas as matérias, sob qualquer um dos acordos multilaterais. Além desse poder decisório amplo, à Conferência Ministerial é garantida, com base no Acordo Constitutivo da OMC, uma série de outros poderes específicos, como: adotar interpretações dos acordos da OMC (artigo XI:2); derrogar a obrigação de um Membro sobre determinado acordo (artigo XI:3); adotar emendas nos acordos (artigo X); decisões sobre ascensão de novos membros (artigo XII); e indicação do Diretor-Geral e adoção de regulações do seu respectivo estafe (artigos VI:2 e VI:3).

À Conferência Ministerial também cabe fazer o lançamento das rodadas de negociações multilaterais. A última rodada lançada foi na Conferência Ministerial de Doha em 2001 e que, até hoje, resta inconclusa.

Com relação ao processo de tomada de decisões no âmbito da Conferência Ministerial, verifica-se uma dualidade de interesses entre a efetividade de formulação de novas regras e o princípio da transparência disposto como premissa de uma eficaz accountability, tendo em vista a dificuldade de se atingir o consenso dentro uma negociação ${ }^{36}$. Por isso, mecanismos alternativos chegaram a ser desenvolvidos durante a Rodada Uruguai para garantir que os acordos saíssem do papel, tal como a tão criticada sala verde ${ }^{37}$.

Diante das duras críticas que os países, em particular os PEDs, teceram ao processo de tomada de decisões na Rodada Uruguai, que foram repetidos durante

35 BOSSCHE, Van den. The law and policy of the World Trade Organization. Cambridge: Cambridge University Press, 2005. p. 123.

36 STEWART, Richard B.; SANCHEZ BADIN, Michelle Ratton. The World Trade Organization and global administrative law. NYU School of Law Public Law Research Paper, Nova Iorque, n. 09-71, p. 1-31, 2009. p. 4-5.

37 Um dos aspectos mais criticados em relação à transparência das negociações da OMC é a chamada Green Room ou Sala Verde, que significa um sistema de reuniões informais estabelecidas durante a Rodada Uruguai, nomeado a partir da cor da sala do Diretor-Geral, que à época que era verde. Nessas reuniões, um pequeno número de países com interesse no assunto a ser negociado se reuniam para a um acordo prévio sobre determinado tema, para depois apresentar um texto formado, a ser ratificado por consenso por todos os países membros. a Conferência Ministerial de Seattle, o lançamento da Rodada Doha levou à articulação de uma série de princípios e práticas para guiar as negociações, sintonizadas no estabelecimento de um Comitê de Negociações Comerciais, em inglês Trade Negotiations Committee (TNC) ${ }^{38}$.

No entanto, apesar dos esforços em tornar a Rodada Doha mais transparente e inclusiva, a forma de organização dos comitês específicos de negociações sofreu críticas por não ter dado oportunidade a todos os membros de colocarem seus interesses em questão ${ }^{39}$.

Apesar disso, é possível afirmar que, os descontentamentos dos países com relação à transparência interna nos processos de tomadas de decisões no âmbito da Conferência Ministerial vêm sendo amenizado ${ }^{40}$.

Prova disso foi o atingimento de um minipacote de acordos inéditos ${ }^{41}$ alcançados durante a última Conferência Ministerial em Bali, após um processo delongado de consultas e reuniões com todos os membros durante meses, culminando no consenso requerido, que permitiu que a OMC entregasse o primeiro acordo multilateral em quase vinte anos de existência.

Apesar de existirem outros dois meios, nos quais podem ser estabelecidos determinados padrões, como no caso dos conselhos e comitês especializados e, em certos aspectos, por meio de interpretação legal por painéis e Órgão de Apelação do Órgão de Solução de Controvérsias da OMC, o mandato de ambos estão previamente definidos nas regras estabelecidas pelos países membros por meio da Conferência Ministerial.

Dessa forma, por meio da Conferência Ministerial, intenta-se fornecer aos seus membros um canal

38 PEREZ-ESTEVE, Maria. WTO rules and practices for transparency and engagement with civil society organizations. Staff Working Paper ERSD, Genebra, v. 14, p. 1-28, 2012. p. 6.

39 STEWART, Richard B.; SANCHEZ BADIN, Michelle Ratton. The World Trade Organization and global administrative law. NYU School of Law Public Law Research Paper, Nova Iorque, n. 09-71, p. 1-31, 2009. p. 4-5.

40 PEREZ-ESTEVE, Maria. WTO rules and practices for transparency and engagement with civil society organizations. Staff Working Paper ERSD, Genebra, v. 14, p. 1-28, 2012. p. 6.

41 Este minipacote alcançou acordos na área de facilitação de barreiras burocráticas alfandegárias, de agricultura - relativo a programas de segurança alimentar - e de incentivos ao desenvolvimento da capacidade estrutural dos países membros menos desenvolvidos. 
democrático de formulação de regras e criações de padrões necessários para a criação de um ambiente comercial multilateral mais legalizado e igualitário.

\subsection{O Mecanismo de Revisão de Políticas Comerciais como cerne no monitoramento e na difusão de informações através da transparência}

Segundo a descrição oficial do site da OMC o Mecanismo de Revisão de Políticas Comerciais 3/4 Trade Policy Review Mechanism (TPRM) 3/4 foi provisoriamente estabelecido em Dezembro de 1988 ainda durante a Rodada Uruguai e foi agregado permanentemente à OMC através do artigo III do Tratado de Marrakesh, entrando em vigor em 1995 (WTO, 2014b). O anexo 3 do Acordo de Marrakesh estabelece como objetivos do TPRM: "facilitar o bom funcionamento do sistema multilateral de comércio, aumentando a transparência das políticas comerciais dos membros" $"$.

O TPRM fornece uma apreciação e avaliação regular coletiva de todas as práticas e políticas comerciais dos membros, assim como os relativos impactos sobre o funcionamento do sistema multilateral de comércio. O seu propósito é atingir ampla transparência e entendimento das políticas e práticas comerciais dos membros e contribuir, nesse sentido, para aumentar a aderência de todos os membros às regras, disciplinas e compromissos feitos sob os acordos da $\mathrm{OMC}^{43}$.

OTPRM também funciona como um mecanismo de supervisão, com uma implicação de aplicação de regras, baseado em uma pressão político-diplomática por parte dos pares, que expõe a responsabilidade da instituição em organizar e manter a vigilância multilateral contra aqueles que intencionam agir em "free riding", enquanto a função de transparência expressa a responsabilidade dos membros em tornar disponíveis as informações sobre as políticas comerciais nacionais em detrimento do seu autointeresse $e^{44}$.

42 BRASIL. Decreto 1.355 de 30 de dezembro de 1994. Promulgo a Ata Final que Incorpora os Resultados da Rodada Uruguai de Negociações Comerciais Multilaterais do GATT. Presidência da República. Brasília, 30, dez. 1994.

43 BOSSCHE, Van den. The law and policy of the World Trade Organization. Cambridge: Cambridge University Press, 2005. p. 94-95.

44 FROESE, Marc D. Between surveillance and transparency: trade policy review and north american dispute settlement at the WTO. Canadian University College, Lacombe, Paper, p. 1-39, abr.
O processo pode ser resumidamente vislumbrado da seguinte forma: os comentários são conduzidos pelo Órgão de Revisão de Políticas Comerciais 3/4 Trade Policy Review Body (TPRB) 3/4 com base em uma declaração política dos Estados que estão sob análise e, um relatório preparado por economistas da Divisão de Revisão de Política Comercial do Secretariado. O debate do TPRB é estimulado por dois examinadores previamente selecionados para este fim. Ao elaborar o seu relatório, o Secretariado busca a cooperação dos Estados, mas tem a responsabilidade pelos fatos apresentados e pontos de vista ${ }^{45}$.

Ressalte-se que o funcionamento do TPBR é meramente administrativo, tendo o mesmo sido concebido com vistas ao exercício político/diplomático de debates e emissões de relatórios que, embora confrontem as políticas comerciais com a legislação da OMC, não podem ser utilizadas de base para o cumprimento de obrigações específicas no âmbito dos acordos ou para procedimentos de resolução de litígios, ou impor novos compromissos políticos sobre membros $^{46}$.

As prerrogativas funcionais do TPRB, portanto, são impostas no sentido de reforçar e legitimar institucionalmente a própria OMC, pois prezam pela observância de princípios como: o da transparência, quando se dá aos membros a oportunidade de conhecer, tecer comentários e, mesmo, questionar as políticas comerciais que vem adotando os seus pares; o da participação, uma vez que todos os membros tem o direito de participar das reuniões do TPBR e; da revisão, tendo em vista que é dada a oportunidade aos membros de analisar diplomaticamente, em conjunto com o Secretariado da OMC e os demais membros, a melhor forma de promover aderência de sua política comercial doméstica às regras comerciais multilaterais, disciplinas e compromissos assumidos no âmbito dos acordos comerciais multilaterais e, quando aplicável, os acordos comerciais plurilaterais. Destacando-se o fato de que vários membros tem tido de revisar sua legislação nacional, adaptando essas às regras da $\mathrm{OMC}$,

2012. p. 7.

45 WTO. Trade policy reviens: brief introduction. Genebra. Disponível em:

<http://wto.org/english/tratop_e/tpr_e/tp_int_e. $\mathrm{htm}>$. Acesso em: 14 fev. 2014a.

46 WTO. Understanding the WTO. Genebra: WTO Publications, 2008. p. 53-55. 
na oportunidade dos seus respectivos relatórios de revisão de política comercial ${ }^{47}$.

O TPRM, no entanto, não perfaz como o único mecanismo de transparência disponível na OMC. Na realidade, a um nível abaixo do TPRM existe a atuação de três conselhos especializados (alguns divididos em comitês) que auxiliam no trabalho de aprimorar a transparência na OMC e promover a vigilância das regras comerciais. São eles: o Conselho para Comércio de Bens; o Conselho para o Comércio de Serviços e o Conselho de TRIPS. O Conselho de Bens é responsável pelo trabalho dos comitês, grupos de trabalho e working parties dos setores de atividade cobertos pelo acordo do GATT, são eles: Agricultura; Acesso ao mercado de bens; Medidas sanitárias e fitossanitárias; Subsídios e medidas de compensação; Antidumping; Avaliação aduaneira; Regras de origem; Licenças de importação; Investimento; Salvaguardas; Empresas comerciais do Estado (grupo de trabalho); e, Acordo de tecnologia da informação ${ }^{48}$.

Além de auxiliar como um mecanismo de supervisão e transparência, os conselhos e comitês também provêm assistência técnica para países em desenvolvimento implementarem seus compromissos da $\mathrm{OMC}^{49}$.

Por último, em resposta à crise financeira global de 2008, o DG Pascal Lamy estabeleceu uma "Força Tarefa sobre a Crise Financeira" dentro do secretariado da OMC, no qual uma das principais tarefas seria a preparação de relatórios sobre o desenvolvimento de políticas relacionadas com o comércio que fossem associadas à crise financeira. A tal iniciativa foi denominada de trade monitoring $g^{50}$.

$\mathrm{Na}$ atual descrição contida no website da OMC dispõe-se que o trade monitoring correntemente produz

47 CHAISSE, Julien; CHAKRABORTY, Debashis. Implementing WTO rules through negotiations and sanction: the role of Trade Policy Review Mechanism and Dispute Settlement System. University of Pennsylvania Journal of International Economic Law, Philadelphia, v. 28, n. 1, 2007.

48 WTO. Understanding the WTO. Genebra: WTO Publications, 2008. p. 101-104.

49 STEWART, Richard B.; SANCHEZ BADIN, Michelle Ratton. The World Trade Organization and global administrative law. NYU School of Law Public Law Research Paper, Nova Iorque, n. 09-71, p. 1-31, 2009. p. 7-8.

50 PAUWELYN, Joost; BERMAN, Ayelet. Emergency action by the WTO director-general: global administrative law and the WTO's initial response to the 2008-09 financial crisis. International Organizations Law Review. v.6, p.499-512, 2009. dois tipos de relatórios de monitoramento de comércio: 1- amplos relatórios sobre a evolução relacionados com o comércio cobrindo todos os membros da OMC e observadores e; 2- relatórios com a Organização para a Cooperação e Desenvolvimento Econômico (OCDE) e da Conferência das Nações Unidas sobre Comércio e Desenvolvimento (UNCTAD) em medidas de investimento e comércio tomadas pelo G-20 $0^{51}$.

Com relação ao princípio da transparência, resta claro que o Diretor Geral estatuiu nesse ponto que o propósito do monitoramento é aumentar a transparência e a pressão dos pares entre os membros de modo a evitar uma mudança em direção ao protecionismo ${ }^{52}$.

Por fim, sempre é possível aos membros acessarem o site oficial da OMC que, conforme será discutido posteriormente, é um ótimo canal de transparência, uma vez que por meio dele os documentos oficiais da OMC são disponibilizados ao público em geral.

Em suma, pode se afirmar que a OMC mune os seus membros com vários mecanismos de transparência e monitoramento para expor aqueles que por ventura estiverem adotando medidas contrárias aos acordos e padrões internacionais. Promove-se, portanto, um sistema de informação eficaz, capaz de identificar abusos ou transgressões do poder que cada membro detém na formulação e regulação das suas respectivas políticas comerciais, tornando possível que este, por conta própria, reconfigure as medidas adotadas para se conformar com os padrões da OMC, ou seja alvo de alguma contenda no sistema de solução de controvérsias, que é o mecanismo capaz de aplicar sanções aos transgressores.

\section{3 Órgão de Solução de Controvérsias como elemento de aplicação de sanções}

É de amplo conhecimento que as negociações da Rodada Uruguai se converteram no sentido de atribuir uma maior independência e autoridade ao antigo sistema de solução de disputas do GATT. A adoção

51 WTO. Trade monitoring. Genebra. Disponível em: < http:// www.wto.org/english/tratop_e/tpr_e/trade_monitoring_e. htm>. Acesso em: 02 mar. 2014b.

52 PAUWELYN, Joost; BERMAN, Ayelet. Emergency action by the WTO director-general: global administrative law and the WTO's initial response to the 2008-09 financial crisis. International Organizations Law Review. v.6, p.499-512, 2009. p. 509. 
do Entendimento sobre a Solução de Controvérsias ${ }^{53}$ (ESC), com o objetivo de indicar à organização os procedimentos do Órgão de Solução de Controvérsias (OSC), teve a intenção de dar um "adensamento da juridicidade" ao novo sistema de solução de controvérsias da OMC, transformando este em um órgão quasi-judicia ${ }^{4}$.

O objetivo básico do Órgão de Solução de Controvérsias da OMC está definido no art. 3.2 do ESC, onde dita que "O sistema de solução de controvérsia da OMC é elemento essencial para trazer segurança e previsibilidade ao sistema multilateral de comércio" 55 .

Uma das características mais marcantes sistema da OMC é a tomada de uma orientação menos conciliatória se comparado ao GATT, apesar de a oportunidade de conciliação ser possível em qualquer fase do processo.

Ademais, é imperioso destacar a criação de um Órgão de Apelação (OA), mecanismo que, além de reforçar o devido processo legal e estabelecer um duplo grau de jurisdição nos conflitos da OMC, permite a interpretação das normas contidas na OMC, produzindo, em cada caso, decisões que solidificam a instituição e dão diretrizes aos membros em futuros litígios.

Nesse sentido, a atuação do OSC é capaz de apontar abusos praticados pelos países em nível de legislação administrativa doméstica, que estejam em desacordo com os princípios e regras do sistema multilateral. O caso mais famoso a tratar esse tipo de situação foi o WT/DS58, US - Shrimp-turtles ${ }^{56}$, em que Índia, Malásia, Paquistão e a Tailândia alegavam que a legislação americana, em relação à Seção 609, proibia a importação de camarões não certificados pelo Turtle Excluder Devices (TEDs), era uma ilegítima extensão da

53 Abreviação de Entendimento Relativo às Normas e Procedimentos sobre Solução de Controvérsias, ou simplesmente o Entendimento sobre a Solução de Controvérsias (ESC) - em inglês: Understanding on rules and procedures governing the settlement of disputes, ou simplesmente Dispute Settlement Understanding.

54 LAFER, Celso. A OMC e a regulamentação do comércio internacional: uma visão brasileira. Porto Alegre: Livraria do Advogado, 1998.

55 Ver: Anexo 2 - Entendimento Relativo às Normas e Procedimentos sobre Solução de Controvérsias. In: BRASIL. Decreto 1.355 de 30 de dezembro de 1994. Promulgo a Ata Final que Incorpora os Resultados da Rodada Uruguai de Negociações Comerciais Multilaterais do GATT. Presidência da República. Brasília, 30, dez. 1994. p. 447.

56 Abreviação de United States — Import Prohibition of Certain Shrimp and Shrimp Products. jurisdição extraterritorial americana e, dessa forma, violava os artigos I, XI e XIII do GATT 1994.

Nesse caso, a decisão final do OA considerou que, embora a medida protetiva ambiental americana fosse válida segundo as normas da OMC, as regras procedimentais que exigiam o TED, no entanto, negava o direito ao devido processo para os países afetados. Em resposta a tal situação, os EUA se tornaram mais flexíveis, passando a prover uma notificação aos países que não se adequassem as exigências do certificado e convidando tais países a prover informações adicionais.

Nessa perspectiva, na visão de Sanchez e Stewart (2009, p. 3) esse mais legalizado sistema de resolução de disputas atraiu um grande volume de negócios e elevou o sistema de solução de controvérsias da OMC a uma posição de liderança entre os tribunais e cortes internacionais.

Porém, o grande trunfo do sistema de resolução de conflitos da OMC é a sua capacidade de impor sanções (também denominada retaliação), algo que restava irrelevante no sistema do GATT, isto porque na época deste último, para se aplicar uma sanção comercial era necessário um consenso positivo, isto é, de todos os membros do GATT. Já na OMC ocorreu uma mudança na forma de composição e adoção das decisões dos painéis do $\mathrm{OA}$, que passaram a ser por consenso negativo, ou seja, somente a rejeição de todos os membros impede a imposição de sanções - conforme artigo 17.14 do $\mathrm{ESC}^{57}$.

A permissão para aplicar uma sanção comercial só ocorre quando verificado que determinado membro falhou no objetivo de mudar a sua política ou legislação comercial, restando esta em dissonância com os acordos da OMC. Assim, se comprovadamente falhar neste aspecto, o membro que foi reclamado deverá compensar o reclamante, na forma de concessões, como, por exemplo, por meio de isenção tributária. $\mathrm{Na}$ falta de uma compensação, o reclamante pode suspender a concessão relativa ao acordo específico que tenha sido ferido, ou na impossibilidade de tal, pode suspender alguma concessão relativa a outro acordo da OMC, neste caso denominada retaliação cruzada.

57 Ver: Anexo 2 - Entendimento Relativo às Normas e Procedimentos sobre Solução de Controvérsias. In: BRASIL. Decreto 1.355 de 30 de dezembro de 1994. Promulgo a Ata Final que Incorpora os Resultados da Rodada Uruguai de Negociações Comerciais Multilaterais do GATT. Presidência da República. Brasília, 30, dez. 1994. p. 461. 
Um dos casos mais emblemáticos de aplicação de sanções comerciais envolve o Brasil e os EUA, no caso US - Subsidies on Upland Cotton (WT/DS267), no qual o Brasil desafiou a legalidade dos subsídios agrícolas americanos destinados à produção e exportação de algodão. Nesse caso, após longos anos de litígio, no dia 22 de agosto de 2009, o "Brasil recebera o direito de aplicar mais de US\$ 800 milhões em retaliação, dos quais mais de US\$200 milhões poderiam tomar a forma de 'retaliação cruzada" 58 .

A possibilidade de aplicar uma retaliação, nos bens e serviços americanos, parece ter sido a única forma de forçar os mesmos a negociarem medidas que pudessem atender as expectativas brasileiras, em direção ao saneamento dos prejuízos causados com os mencionados subsídios. Neste ponto, é importante ressaltar que a retaliação pode ser mais válida como um poder de barganha em si, que seja capaz de forçar o país infrator a negociar as suas políticas, do que uma medida de cunho indenizatório para amenizar prejuízos.

Em função do exposto, na autoavaliação da OMC, o sistema de solução de controvérsias representa um grande sucesso, quebrando paradigmas existentes na época do GATT, fortalecendo a instituição através da formulação da jurisprudência do OA impedindo o congelamento das regras e atribuindo segurança e previsibilidade ao comércio internacional. No entanto, se admite que a participação dos PEDs não seja satisfatória ${ }^{59}$ devido as custas judiciais, por medo de represália dos países desenvolvidos ou até por incapacidade de impor medidas de compensação à violação sofrida ${ }^{60}$.

Assim, resta patente que com a promoção de um sistema de solução de controvérsias dotado de um processo caracterizado pela juridicidade, que promova a observância de princípios administrativos, como

58 SCHMIDT, Luis Felipe Flores. A construção da retaliação brasileira no caso algodão: os desafios do pioneirismo. In: BENJAMIN, Daniela Arruda (Org.). O sistema de Solução de Controvérsias da OMC: uma perspectiva brasileira. Brasília: FUNAG, 2013. p. 631.

59 Ainda assim, se comparado ao GATT, nos 10 primeiros anos de funcionamento do OSC da OMC, os PEDs incrementaram sua participação no sistema de solução de controvérsias da OMC, uma vez que no antigo sistema, 30\% das demandas foram apresentadas exclusivamente por PEDs e na OMC, esta cifra elevou-se para 39\%.

60 WTO. The future of the WTO: addressing institutional challenges in the new millennium. Genebra: WTO publications, 2004. transparência, participação, decisão motivada e revisão, e, que assegure aos países membros a imposição de retaliações comerciais, uma vez que se comprove uma prática comercial abusiva, pode ser identificado como um eficaz elemento de aplicação de sanções.

Portanto, com base em todo exposto, de forma geral é factível identificar que, numa perspectiva intergovernamental, além de notadamente atuar como um fórum de negociações internacionais e um órgão administrativo internacional, a OMC também carrega todos os elementos que a caracterizam como um mecanismo per si de promoção de accountability interna do regime de comércio internacional - estabelecimento de padrões por meio da Conferencia Ministerial, ampla difusão de informações e aplicação eficaz de sanções pelo OSC - de forma a corroborar a promoção de transparência, participação nos processos de tomadas de decisões e regulação e aplicação de mecanismos de revisão. Nestes termos, pode-se confirmar que o exercício de accountability horizontal da OMC é sólido e, por isso o seu sistema é funcional e legítimo.

\section{Elementos de accountability na OMC sob uma perspectiva vertical}

Conforme foi descrito na sessão anterior, a OMC também pode ser entendida em sua dimensão interna como um mecanismo per si de accountability horizontal. Entretanto, quando adotada uma abordagem supranacionalista da atuação da OMC, elenca-se a sociedade civil como o destinatário final dos processos de estabelecimento de regras e padrões e tomadas de decisões no âmbito do comércio internacional. Em virtude disso, constrói-se um argumento em prol da promoção de canais de participação, transparência e de consultas junto à sociedade civil no intuito de promover a accountability e, dessa forma, superar os déficits de legitimidade apontados na organização.

Nesse quesito, existem questionamentos acerca da possibilidade de criação de um mecanismo de accountability independente na OMC, voltado à sociedade civil, nos moldes estabelecidos pelos bancos de desenvolvimento, em particular o Painel de Inspeção do Banco Mundial, com vistas permitir que os atores não membros tenham a oportunidade de questionar $o$ cumprimento das suas políticas operacionais ${ }^{61}$.

61 LESTER, Simon. Accountability at the WTO. International Economic Law and Policy Blog. 13 dez. 2009. Disponível em: <http://worldtradelaw.typepad.com/ielpblog/2009/12/ 
No entanto, diferentemente do Banco Mundial, que age como um verdadeiro "ator no mercado de capitais" 62 $3 / 4$ semelhante a um banco privado, na medida em que promove um serviço, que diretamente afeta a vida de uma população inteira $3 / 4$ as iniciativas da OMC partem de sua lógica member-driven e, portanto, não são independentes como as do Banco Mundial. Reitera-se, portanto, o caráter de fórum e agência administrativa da OMC em função dos seus membros.

Porém, desde a sua criação, a OMC vem intensificando as formas de aproximação e engajamento junto à sociedade civil, em particular as ONGs que atuam nas áreas contempladas pela OMC e que se baseiam em Genebra.

Assim, uma vez insusceptível a criação de um mecanismo de accountability próprio direcionado a sociedade civil, nas próximas sessões se analisará, de forma análoga a qual foi feita na accountability horizontal, a existência, ou não, dos elementos de accountability, que porventura sejam capazes de atender aos requerimentos da promoção de uma accountability vertical.

\subsection{A participação da sociedade civil na OMC}

Primeiramente, é importante destacar que, tanto na literatura acadêmica relativa à OMC, como nos documentos oficiais da OMC, falar de sociedade civil é quase sinônimo de se falar em $\mathrm{ONGs}^{63}$. Podese depreender que isso ocorre devido ao maior interesse dessa parcela da sociedade civil, que trabalha ativamente em temas relacionados ao comércio internacional, tais como direitos humanos, direitos trabalhistas, meio ambiente e desenvolvimento. E, em função deste interesse mais sobressaliente por parte das ONGs, conforme será exposto abaixo, as disposições oficiais da OMC relativas ao seu engajamento com a sociedade civil, em sua grande maioria fazem referência especificamente às ONGs.

accountability-at-the-wto.html>. Acesso em: 15 jan. 2014.

62 BAIMU, Evarist; PANOU, Aristeidis. Responsibility of International Organizations and the World Bank Inspection Panel: parallel tracks unlikely to converge? In: CISSE, Hassane; BRADLOW, Daniel D.; KINGSBURY, Benedict. The World Bank legal review: international financial institutions and global legal governance. Washington: The World Bank, 2012. v. 3.

63 Ver por exemplo: HALLE, Mark; WOLFE, Robert; BEATON, Christopher. Looking back, looking forward: civil society contributions to WTO accountability. ENTWINED Issue Brief, n. 8, 2011.
A esse respeito, Craig Vangrasstek ${ }^{64}$ exalta o reconhecimento das ONGs como atores nas relações internacionais é anterior à OMC e mesmo ao GATT, tendo-se, como exemplo, o artigo 71 da Carta das Nações Unidas, que autorizou o Conselho Econômico e Social a adotar as diligências necessárias para a consulta com organizações não governamentais que se ocupem de assuntos de sua competência. Mesmo a Carta de Havana, da idealizada International Trade Organization (ITO), similarmente previa consultas com ONGs, de acordo com o artigo 87.2, que estatuía: "The Organization may make suitable arrangements for consultation and co-operation with non-governmental organizations concerned with matters within the scope of this Charter" ${ }^{65}$. Porém, uma vez que a ITO não teve êxito em se estabelecer e, ao seu substituto, o GATT, não foi incluída nenhuma previsão legal de estabelecimento de relações com as organizações da sociedade civil, a estas nunca foi dado acesso direto as atividades daquela.

Todavia, o estabelecimento da OMC tratou de corrigir a ausência de uma previsão legal concernente à relação com a sociedade civil, estabelecendo em seu Acordo Constitutivo no Artigo V:2, que se refere as Relações com Outras Organizações, que "O Conselho Geral poderá tomar as providências necessárias para manter consultas e cooperação com organizações não governamentais dedicadas a assuntos relacionados com os da OMC" ${ }^{\prime 6}$.

No entanto, ao passo que o Artigo V:1 estabelece que "O Conselho Geral tomará as providências necessárias para estabelecer cooperação efetiva com outras organizações intergovernamentais que tenham áreas de

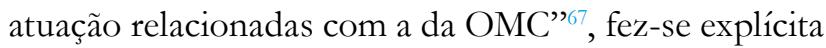

64 VANGRASSTEK, Craig. The history and the future of the World Trade Organization. Genebra: WTO Publications, 2013.

65 UNITED NATIONS CONFERENCE ON TRADE AND EMPLOYMENT. Final Act and Related Documents. Interim Comission for the International Trade Organization: Lake Success, abr. 1948. p. 85.

66 Acordo Constitutivo da Organização Mundial do Comércio. In: BRASIL. Decreto 1.355 de 30 de dezembro de 1994. Promulgo a Ata Final que Incorpora os Resultados da Rodada Uruguai de Negociações Comerciais Multilaterais do GATT. Presidência da República. Brasília, 30, dez. 1994.

67 Acordo Constitutivo da Organização Mundial do Comércio. In: BRASIL. Decreto 1.355 de 30 de dezembro de 1994. Promulgo a Ata Final que Incorpora os Resultados da Rodada Uruguai de Negociações Comerciais Multilaterais do GATT. Presidência da República. Brasília, 30 dez. 1994. 
a opção pela organização de ter como preferência a relação com outras organizações intergovernamentais em detrimento das $\mathrm{ONGs}^{68}$.

Conforme classificação observada pela Professora Michelle Ratton Sanchez Badin ${ }^{69}$, em geral, as formas de participação em fóruns intergovernamentais podem ser classificadas em quatro categorias: (1) informação, (2) consulta, (3) cooperação, e (4) deliberação. No Acordo Constitutivo da OMC, estão expressamente discriminadas as formas de consulta e cooperação com as ONGs. No entanto, ficam ausentes critérios de deliberação, uma vez que os países membros detêm o monopólio deste e, em termos de informação, esta é parte do princípio da transparência, um dos pilares da organização e, portanto destinados a todos de forma erga omnes.

Porém, uma vez que apenas essa passagem legal, contida no Acordo Constitutivo, não promovia um direcionamento explícito sobre quais procedimentos a OMC deveria tomar em relação ao seu engajamento com a sociedade civil $^{70}$, em 1996 foi adotado pelo Conselho Geral as Linhas Gerais para Arranjos sobre Relações com Organizações Não governamentais - em inglês, Guidelines for arrangements on relations with NonGovernmental Organizations (WT/L/162 de 23 de Julho de 1996) - de agora em diante referida apenas como Linhas Gerais de 1996.

Conforme resume Peter Van den Bossche, nas Linhas Gerais de 1996, foi acordado que a interação com as ONGs deveria ser desenvolvida por meio de vários meios como: a organização de simpósios para ONGs em questões específicas relacionadas à $\mathrm{OMC}$; arranjos informais que permitam receber informações das ONGs devendo essas informações serem disponíveis a consultas por delegações interessadas; a continuação da prática passada do secretariado da OMC em responder a requerimentos por informações gerais e briefings sobre a OMC, e; a participação dos presidentes de conselhos

68 VANGRASSTEK, Craig. The history and the future of the World Trade Organization. Genebra: WTO Publications, 2013. p. 181.

69 SANCHEZ BADIN, Michelle Ratton. Breves considerações sobre os mecanismos de participação para ONGs na OMC. Revista Internacional de Direitos Humanos, n. 4, ano 3, p. 102-125, 2006. p. 105.

70 PEREZ-ESTEVE, Maria. WTO rules and practices for transparency and engagement with civil society organizations. Staff Working Paper ERSD, Genebra, v. 14, p. 1-28, 2012. p. 10. e comitês da OMC em discussões e encontros com ONGs em seus próprios estabelecimentos ${ }^{71}$.

Por outro lado, as Linhas Gerais de 1996 também delimitaram o alcance do envolvimento das ONGs. No parágrafo de conclusão, o conselho geral ser refere ao caráter especial da OMC que é legalmente vinculada aos membros por um tratado intergovernamental de direitos e obrigações e como um fórum de negociações e, portanto, existe uma clara visão de que não é possível para as ONGs estarem diretamente envolvidas nos trabalhos da OMC ou suas reuniões, apesar de ser aconselhável a utilização de consultas e outras formas de cooperação com estas ${ }^{72}$.

Em resumo, apesar de estabelecer regras que passaram a conduzir o relacionamento da OMC com as ONGs $3 / 4$ e, em função disso reconhecer o importante papel que as podem ter em tornar o público mais lúcido com relação às práticas observadas na $\mathrm{OMC}^{3} / 4$ as Linhas Gerais de 1996 estabeleceram limites para a referida relação da OMC com as ONGs. Maria Perez-Esteve elenca três limites para a supracitada relação: primeiro, as Linhas Gerais de 1996 explicitamente se referem ao caráter especial da OMC de ser, ao mesmo tempo, um tratado intergovernamental, legalmente vinculante, de direitos e obrigações entre os seus membros, e, um fórum de negociações; em segundo lugar, reconhece a difundida visão entre os membros que não seria possível para as ONGs estarem diretamente envolvidas no trabalho da OMC ou suas reuniões, e; por último, é especificado que uma consulta e uma cooperação próxima com as ONGs também podem ser construtiva no contexto doméstico entre os governos dos países membros e a sociedade civil, uma vez que é neste nível que se encontra a responsabilidade primária de levar em conta os diferentes elementos do interesse público ${ }^{73}$.

É importante ressaltar que os princípios estabelecidos nas Linhas Gerais de 1996 não foram

71 BOSSCHE, Van den. The law and policy of the World Trade Organization. Cambridge: Cambridge University Press, 2005. p. 158.

72 WTO. WT/L/162. Guidelines for arrangements on relations with Non-Governmental Organizations. Genebra, 23 jul. 1996. Disponível em:

<http://www.wto.org/english/forums_e/ngo_e/ guide_e.htm>. Acesso em: 20 fev. 2014.

73 PEREZ-ESTEVE, Maria. WTO rules and practices for transparency and engagement with civil society organizations. Staff Working Paper ERSD, Genebra, v. 14, p. 1-28, 2012. 
alterados e permanecem até hoje em vigor. Assim, para uma participação da sociedade civil para além do que já foi estabelecido, é necessário encontrar alternativas dentro da estrutura organizacional da OMC baseada nos acordos já estabelecidos, ou alcançar a decisão consensual de todos os países membros, para uma regra mais direta de inclusão das ONGs.

\subsection{Estabelecimento de padrões}

Conforme foi visto anteriormente, o estabelecimento de regras na OMC se dá por meio das Conferências Ministeriais, nas quais os países membros detêm a exclusividade de negociar novos acordos comerciais por meio do consenso. A sociedade civil não pode participar diretamente da parte deliberativa das Conferências Ministeriais, mas isso não a impede de tentar exercer algum tipo de influência nas negociações.

A partir do estabelecimento das Linhas Gerais de 1996, toda ONG ou entidade da sociedade civil organizada que demonstrasse estar à frente de alguma questão relacionada à OMC, poderia pedir o credenciamento para integrar uma lista montada previamente a conferência, que era submetida ao Conselho Geral para a aprovação. Após isso, a tendência geral foi de aumento no número de participantes da sociedade civil nas Conferências Ministeriais, embora a localização do encontro também influenciasse nos níveis de participação.

Neste sentido, com exceção da Conferência Ministerial de Doha, que se envolveu uma série de restrições devido ao atentado de 11 de setembro, a organização das Conferencias Ministeriais tem anotado um grande interesse e participação da sociedade civil ${ }^{74}$.

\footnotetext{
74 Na Conferência de Singapura, em 1996, 108 grupos da sociedade civil participaram (cada um sendo permitido até 3 representantes). Esse número subiu para 128 associações na Conferência Ministerial de Genebra 1998, e 737 organizações na Reunião Ministerial de Seattle no final de 1999. O número caiu para 366 para a conferência da (relativamente remota) Doha, que, aliás, foi convocada em meio as reduções de viagens aéreas após 9/11 e envolveu uma série de restrições burocráticas que complicaram a participação da sociedade civil. No encontro em Cancún, registraram-se 902 organizações, e 812 grupos participaram da Conferência Ministerial de Hong Kong em 2005. Em: WILLIAMS, Mark. Civil society and the WTO: contesting accountability. In: SCHOLTE, Jan Aart (Ed.). Building global democracy: civil society and global governance. Cambridge: Cambridge University Press, 2011. p. 105-127.
}

Neste aspecto, conforme expõe Peter Van den Bossche apesar de terem sido convidadas a presenciarem as sessões plenárias da primeira Conferência Ministerial pós-criação da OMC, e terem a oportunidade de participarem de workshops organizados pela OMC que ocorreram paralelamente à conferência, as ONGs não tiveram reconhecido o status de observador e, muito menos, a elas foi permitido fazer qualquer tipo de declaração ${ }^{75}$. Ademais, conforme fora colocado, elas só poderiam atender as sessões plenárias, que representam apenas a parte mais formal da Conferência Ministerial, sendo proibidas de participarem das negociações.

Uma segunda onda de melhorias aconteceu em abril de 2001, quando o secretariado da OMC lançou uma nota de informações aos membros, denominada $W T O$ Secretariat Activities with NGOs, expondo uma nova gama de iniciativas em empreendimentos com ONGs para a preparação da quarta Conferência Ministerial em Doha. Conforme expõe Michelle Ratton Sanchez Badin, dentre as formas de atividades possíveis, destacam-se: “(1) os briefings, em Genebra, pelo Secretariado após as reuniões entre os Membros; (2) as pequenas mesas de debate; (3) a organização de grupos de trabalho; e (4) a possibilidade de aceitação pelo Secretariado de posições por escrito" 7 .

A intenção do novo programa de atividades era facilitar e incentivar discussões substantivas e responsáveis com as ONGs sobre as questões abrangidas pelo mandato da OMC. Nesta perspectiva, desde 2001 a OMC tem facilitado a realização de um simpósio ou de um fórum público anual ${ }^{77}$. Esses eventos geralmente

75 BOSSCHE, Van den. The law and policy of the World Trade Organization. Cambridge: Cambridge University Press, 2005.

76 SANCHEZ BADIN, Michelle Ratton. Breves considerações sobre os mecanismos de participação para ONGs na OMC. Revista Internacional de Direitos Humanos, n. 4, ano 3, p. 102-125, 2006. p. 110.

77 Os Fóruns Públicos da OMC em ordem cronológica decrescente: 2013: 1-3 October "Expanding Trade through Innovation and the Digital Economy"; 2012: 24-26 September "Is Multilateralism in Crisis?"; 2011 "Seeking answers to global trade challenges"; 2010 "The Forces Shaping World Trade"; 2009 "Global Problems, Global Solutions: Towards Better Global Governance"; 2008 "Trading into the Future"; 2007 "How the WTO can help harness globalization?"; 2006 "What WTO for the XXIst Century?". The Public Forum was previously known as the Public Symposium, which was first held in 2001: 2005 "WTO After 10 Years: Global Problems and Multilateral Solutions"; 2004 "Multilateralism at a crossroads"; 2003 "Challenges Ahead on the Road to Cancún"; 2002 "The Doha Development Agenda and beyond"; 2001 "Symposium on 
servem para a exposição dos pontos de vista das ONGs, mas sem a existência de um compromisso que leve a um diálogo significante. Ademais, a participação limitada dos oficiais dos membros da OMC indica que estes eventos não são efetivos no exercício de consultas substantivas $^{78}$.

Um canal adicional de consulta junto à sociedade é provido por meio de reuniões informais entre ONGs e oficiais da OMC. Outrossim, desde 1996 a Divisão de Relações Externas da OMC vem mantendo contato com ONGs e distribuindo briefings regulares a estas. $\mathrm{Na}$ ausência de acesso da sociedade civil às deliberações do Conselho Geral e outros órgãos, os briefings acabam sendo uma importante fonte de informação.

Por último, ocorreram três tentativas de um contato mais sistemático entre o Diretor Geral e membros da sociedade civil, em especial representantes de ONGs. A primeira foi com o Diretor Geral Renato Ruggiero, que introduziu a prática de manter reuniões informais regulares com diferentes representantes de $\mathrm{ONGs}^{79}$. Em 2003, o Diretor Geral Supachai Panitchpadki estabeleceu um Informal NGO Advisory Body e um Informal Business Advisory Body, mas não resta claro se estes mecanismos consultivos tiveram alguma consequência política, sem contar que estes expiraram com o término do mandato de Supachai Panitchpadki, sem terem sido renovados ${ }^{80}$. A terceira tentativa foi estabelecida junto com o Diretor Geral Pascal Lamy, no qual ele comunicou ao estafe da OMC a sua intenção de ampliar as práticas de engajamento e transparência junto as ONGs e a sociedade civil por meio de um relatório perene às $\mathrm{ONG}$ e ao público em geral com a explicação das regras e atividades da $\mathrm{OMC}^{81}$.

Após os programas delineados pelo Diretor Geral, o número de práticas de engajamento da OMC junto à

issues confronting the world trading system".

78 WILLIAMS, Mark. Civil society and the WTO: contesting accountability. In: SCHOLTE, Jan Aart (Ed.). Building global democracy: civil society and global governance. Cambridge: Cambridge University Press, 2011. p. 117.

79 PEREZ-ESTEVE, Maria. WTO rules and practices for transparency and engagement with civil society organizations. Staff Working Paper ERSD, Genebra, v. 14, p. 1-28, 2012. p. 14.

80 BOSSCHE, Van den. The law and policy of the World Trade Organization. Cambridge: Cambridge University Press, 2005.

81 PEREZ-ESTEVE, Maria. WTO rules and practices for transparency and engagement with civil society organizations. Staff Working Paper ERSD, Genebra, v. 14, p. 1-28, 2012. sociedade civil aumentou ${ }^{82}$, no entanto, nenhum modelo desenhado implicou uma inclusão direta da sociedade civil no processo de tomada de decisões e produção de regras. Por outro lado, pode-se inferir que quanto mais envolvimento e contato a sociedade civil passar a ter com a OMC, mais conhecimento esta agregará voltado a pressionar, não só a OMC como organização, mas, em especial, os Estados que a compõem e que procuram estabelecer regras em desacordo com os intuitos das respectivas representações da sociedade civil.

\subsection{Transparência na prática de difusão de informações}

É possível identificar na OMC dois tipos distintos de transparência: a transparência interna e a transparência externa. A interna diz respeito às práticas de transparência dos países membros entre si e, entre os países membros e o corpo administrativo componente da OMC. Já a transparência externa se refere à prática de manter o público em geral informado das atividades e trabalhos da OMC.

A transparência entre os membros sempre foi um requisito básico desde a época do GATT ${ }^{83}$, porém, este requisito foi expandido na OMC, uma vez que todos os acordos da OMC requerem que os governos notifiquem ao Secretariado da OMC, medidas comerciais ao nível nacional, novas ou modificadas, antes de estas serem implementadas:

Conforme já foi visto, a prática central para assegurar a transparência entre os membros da OMC ocorre por meio do exercício de revisão de pares em comitês e órgãos que atuem nessa área. Notadamente, o mecanismo de supervisão regular das políticas comerciais nacionais é o TPRM, que estabelece revisões periódicas de todos os membros.

Outra forma de incrementar a transparência interna se dá, por meio da notificação cruzada, meio pelo qual um membro notifica a OMC de uma medida que não foi notificada por outro membro. Isto é possível sob o Acordo de Medidas de Salvaguarda e Direitos Compensatórios e no Mecanismo de Transparência do Regional Trade Agreement.

82 PEREZ-ESTEVE, Maria. WTO rules and practices for transparency and engagement with civil society organizations. Staff Working Paper ERSD, Genebra, v. 14, p. 1-28, 2012.

83 Contida no artigo $\mathrm{X}$ do GATT sobre Publicação e Administração de Regulações Comerciais. 
Conforme explicita Michelle Ratton Sanchez Badin, o primeiro documento da OMC em que se pode identificar a garantia da transparência externa é o WT/L/160/Rev.1 de 1996, relativa aos procedimentos para circulação e liberalização dos documentos na organização, uma vez que existia diferença com relação ao tempo de liberação de documentos caso a transparência fosse interna ou externa, na qual os documentos da OMC, só poderiam ser liberados ao público seis meses após serem discutidos e negociados entre os Membros nos Conselhos e Comitês ${ }^{84}$. Ainda assim, o referido documento não garantiu uma plena liberação de documentos oficiais da OMC uma vez que este princípio foi, na época, sujeito a exceções importantes, tais como a liberação de Atas de reuniões do Secretariado da OMC só poderem ser liberados após o decurso de oito a nove meses ${ }^{85}$.

No entanto, um fato teve importância marcante no rumo pelo qual a OMC passaria a ter com a sociedade civil, em especial as ONGs: o fiasco da Conferência Ministerial de Seattle. Um ano após a denominada batalha de Seattle ${ }^{86}$, o Conselho Geral manteve intensivas reuniões informais com os países membros com a intenção de debater a sua transparência externa, especificamente a questão da participação da sociedade civil e ONGs no trabalho da OMC, dando início aos trabalhos de revisão da WT/L/160/Rev.1.

84 SANCHEZ BADIN, Michelle Ratton. Breves considerações sobre os mecanismos de participação para ONGs na OMC. Revista Internacional de Direitos Humanos, n. 4, ano 3, p. 102-125, 2006.

85 BOSSCHE, Van den. The law and policy of the World Trade Organization. Cambridge: Cambridge University Press, 2005.

86 A batalha de Seattle foi a denominação dada para a série de manifestações que ocorreram durante a Conferência Ministerial de Seattle, na qual se estima que mais de quarenta mil pessoas, saíram as ruas para manifestar contra a forma pela qual a OMC estava guiando questões de interesse a humanidade, tais como saúde, desenvolvimento e meio ambiente. As manifestações direcionadas contra a OMC foram incrementadas por outras manifestações que ocorriam concomitantemente em Seattle, em especial de trabalhadores grevistas, resultando em um aumento significativo do número de manifestantes. A par disso, a atuação de black blocs e outros grupos radicais transformaram as manifestações em motim O resultado foi a classificação de estado de sítio, que fez com que o Departamento de Polícia e a Guarda Nacional acabassem usando de repreensão excessiva contra manifestantes e mesmo equipes jornalísticas, transformando o que antes eram manifestações em um cenário de guerra. Para um aprendizado mais interativo sobre o tema, ver o filme: BATTLE of Seattle. Direção: Stuart Townsend. Hyde Park International, 2007.
Em 2002 foi, então, aprovada a Decisão WT/L/452, que revisou a WT/L/160/Rev.1 e atenuou o descompasso entre os períodos de tempo para a liberação dos documentos, definindo como regra geral que os documentos da OMC seriam automaticamente liberados ao público ${ }^{87}$.

O principal canal de transparência entre a OMC e a sociedade civil vem sendo feito através do website da OMC. O uso deste como ferramenta de transparência remete as linhas gerais de 1996 e, posteriormente, a decisão do Conselho Geral, em 2002, sobre os procedimentos para a circulação e liberação de documentos da OMC, onde foi permitido que mais documentos fossem acessíveis ao público e de forma mais rápida. Desde 1998, o website tem também mantido uma sessão especial para ONGs, o qual contém informações gerais sobre as atividades da OMC, relações com as aquelas, participação da sociedade civil nas Conferências Ministeriais e documentos recebidos de representações da sociedade civil.

$\mathrm{O}$ acesso às notificações, que contém informações sobre as políticas e práticas comerciais dos membros, fornece às empresas do setor privado estabilidade e previsibilidade para conduzir os seus negócios, ao mesmo tempo em que fornece, ao público geral e às ONGs envolvidas em comércio internacional, informações que possam ser usadas para manter os governos accountable por suas ações ${ }^{88}$.

Desta forma, pode-se afirmar que o uso do website da OMC, como forma de incrementar a transparência externa da organização, junto às ONGs, sociedade civil e público em geral, vem sendo bem-sucedido, uma vez que a disseminação de documentos via website na OMC foi uma história de sucesso na qual o volume de documentos e o fácil acesso levaram de 15 a 20 milhões de acessos por mês e downloads de mais de 25 milhões de páginas ${ }^{89}$.

87 SANCHEZ BADIN, Michelle Ratton. Breves considerações sobre os mecanismos de participação para ONGs na OMC. Revista Internacional de Direitos Humanos, n. 4, ano 3, p. 102-125, 2006.

88 PEREZ-ESTEVE, Maria. WTO rules and practices for transparency and engagement with civil society organizations. Staff Working Paper ERSD, Genebra, v. 14, p. 1-28, 2012.

89 SMYTHE, Elizabeth; SMITH, Peter J. Legitimacy, transparency, and information technology: the World Trade Organization in an era of contentious trade politics. In: Global governance: a review of multilateralism and international organizations, v. 12 , n. 1, p. 31-53, jan. 2006. 
Ocorre que, com relação ao TPRM, que é o principal órgão promotor da transparência interna na OMC, nem a sociedade civil organizada, muito menos o público em geral tem acesso as suas reuniões. Da mesma forma ocorre com relação ao trabalho quotidiano dos Conselhos e Comitês da OMC. "Para nenhum dos órgãos envolvidos na aplicação de regras há a previsão de participação de ONGs nos documentos oficiais da OMC"

Na visão da Professora Michelle Sanchez Badin, podem ser levantadas pelo menos três hipóteses para explicar a falta de um debate mais amplo sobre a inclusão da sociedade civil no TPRM e comitês da OMC: "(1) pouca demanda; (2) menor responsividade da OMC quanto a essa forma de regulamentação; e/ ou (3) uma certa conveniência da informalidade para ONGs mais influentes" ".1. Com base em suas pesquisas, a referida autora afirma que todas as três hipóteses podem ser confirmadas.

\subsection{A participação da sociedade civil no processo de enforcement das regras pelo Órgão de Solução de Controvérsias}

A participação da sociedade civil nos processos de resolução de conflitos no âmbito do Órgão de Solução de Controvérsias da OMC foi construída em torno de um grande debate acerca da aceitação, ou não, das submissões provenientes dos denominados amicus curiae, ou em português, "amigo da corte" ${ }^{92}$.

90 SANCHEZ BADIN, Michelle Ratton. Breves considerações sobre os mecanismos de participação para ONGs na OMC. Revista Internacional de Direitos Humanos, n. 4, ano 3, p. 102-125, 2006. p. 111.

91 SANCHEZ BADIN, Michelle Ratton. Breves considerações sobre os mecanismos de participação para ONGs na OMC. Revista Internacional de Direitos Humanos, n. 4, ano 3, p. 102-125, 2006. p. 111-112.

92 "Desde o início do século XX, o instituto jurídico denominado Amicus Curiae ("Amigo da Corte") é adotado na Suprema Corte norte-americana, objetivando proteger direitos coletivos (de grupos identificados) ou de proteger direitos difusos (da sociedade em geral). Sua função é chamar a atenção dos julgadores para alguma matéria que poderia, de outra forma, escapar-lhe ao conhecimento. Um memorial de amicus curiae é produzido, assim, por quem não é parte no processo, com vistas a auxiliar a Corte para que esta possa proferir uma decisão acertada, ou com vistas a sustentar determinada tese jurídica em defesa de interesses públicos e privados de terceiros, que serão indiretamente afetados pelo desfecho da questão". SILVA, Luiz Fernando Martins da. Amicus Curiae: direito e ação afirmativa. Revista Jurídica, Brasília, v. 7, n. 76, p.70-78, 2006. p. 70.
$\mathrm{Na}$ OMC, a primeira vez que se lidou com as submissões de amicus curiae foi no caso US-Gasoline (WT/DS2), no entanto, o painel decidiu seguir os procedimentos do antigo GAT'T, e não considerou os briefs. Foi somente no caso US-Shrimp (WT/DS58), em que Índia; Malásia; Paquistão e Tailândia questionavam a política americana de importação de camarões, que o debate sobre a participação da sociedade civil organizada, através de documentos não solicitados, entrou em pauta no Órgão de Solução de Controvérsias da OMC, muito em função da grande repercussão que este caso teve perante ONGs de cunho ambiental ${ }^{93}$.

Nessa oportunidade, o painel entendeu que embora detivesse a permissibilidade do artigo 13 do ESC para buscar informações, quando necessário, de qualquer fonte relevante, a aceitação de documentação por parte de entidades não integrantes da OMC não haveria de ser permitida, na oportunidade de não solicitação de sua submissão por parte do painel. No entanto, o painel ressaltou que os documentos de amicus curiae que fossem integrados às petições dos membros, passavam a ser parte desta e, portanto, deveriam ser aceitas em sua completude ${ }^{94}$

Apesar de ter concordado com o posicionamento do painel, de que só os países membros poderiam ser partes legítimas na solução de conflitos, o Órgão de Apelação reverteu o entendimento daquele com relação às documentações não solicitadas, oriundas de terceiros não membros da OMC, ampliando o entendimento da palavra buscar, permitindo que em virtude da possibilidade de iniciativa própria do painel em auferir informações adicionais, este poderia também se utilizar, se bem entendesse proveniente, das documentações dos amicus curiae ${ }^{95}$.

93 Foram apresentados documentos por diversas ONGs, como, por exemplo, a WWF, reiterando a ameaça da pesca predatória de camarão às tartarugas marinhas e expondo políticas e leis nacionais, regionais e internacionais relacionada à preservação da espécie. Outras submissões foram feitas pelo Centro de Direito Ambiental Internacional e pelo Centro de Preservação Marinha. Ver: PALMER, Alice. Observando de fora: participação da sociedade civil no Sistema de Solução de Controvérsias da OMC. In: BAPTISTA, Luiz Olavo; CELLI JUNIOR, Umberto; YANOVICH, Alan (Orgs.). 10 anos de OMC: uma análise do Sistema de Solução de Controvérsias e perspectivas. São Paulo: Aduaneiras, 2007. p. 223-258.

94 MAVROIDIS, Petros C. Amicus curiae briefs before the WTO: much ado about nothing. Jean Monnet Working Paper, v. 2, n. 1, p. 1-18, 2002.

95 WTO. WT/DS58/AB/R - United States - Import Probibition of Certain Shrimp and Shrimp Products. Genebra, 12 out. 1998, p. 38. 
No caso US - Carbon Steel (WT/DS138)96, o OA reconheceu que a oportunidade dos amicus curiae de submeterem suas petições e documentos se dava tanto na fase de painel, quanto na fase de apelação, uma vez que a permissividade contida no artigo 13.2 do ESC, se estendia a este último.

Posteriormente, no caso EC - Abestos (WT/ DS135 $)^{97}$, o OA promoveu o desenvolvimento de alguns procedimentos específicos para o recebimento dos documentos submetidos pelos amicus curiae, tomando como base o artigo 16(1) do seu Working Procedures ${ }^{98}$.

Nesse caso, ficou institucionalizada a possibilidade de participação da sociedade civil nos procedimentos de solução de controvérsias da OMC, por meio de um processo burocrático, que acabou por instrumentalizar, mas ao mesmo tempo dificultar, a aceitação de briefs dos amicus curiae ${ }^{99}$. O estabelecimento de procedimentos adicionais por parte do OA causou grande discordância por parte de vários PEDs, tanto que resultou na convocação de uma Reunião Especial do Conselho Geral o (WT/GC/M/60) no dia 22 de novembro de 2000, na qual foi debatida a atitude do OA.

O OA ainda decidiu, no caso WT/DS231 EC Trade Description of Sardines, que aos países membros também era assegurada a possibilidade de submeter documentos na forma de amicus curiae, atendendo a um pedido da delegação ${ }^{100}$.

96 WTO. WT/DS138/AB/R. United States - Imposition of Countervailing Duties on Certain Hot-Rolled Lead and Bismuth Carbon Steel Products Originating in the United Kingdom. Genebra, 10 maio 2000. (Também conhecido como US Bismuth ou US - British Steel).

97 WTO. WT/DS135/AB/R. European Communities - Measures Affecting Asbestos and Products Containing Asbestos. Genebra, 12 mar. 2001.

98 Conjunto de regras que definem a forma de atuação do Órgão de Apelação no Sistema de Solução de Controvérsias.

99 Nesse caso o OA recebeu 17 pedidos de terceiros não partes para a aplicação de suas briefs, no entanto todas elas foram rejeitadas. Seis delas devido ao fato de terem sido consideradas intempestivas, porém o restante dos pedidos foram negados sem um motivo específico, apenas com a declaração do OA que não havia satisfeito todos os requerimentos dos procedimentos adicionais. Ver: PALMER, Alice. Observando de fora: participação da sociedade civil no Sistema de Solução de Controvérsias da OMC. In: BAPTISTA, Luiz Olavo; CELLI JUNIOR, Umberto; YANOVICH, Alan (Orgs.). 10 anos de OMC: uma análise do Sistema de Solução de Controvérsias e perspectivas. São Paulo: Aduaneiras, 2007. p. 223-258.

100 UNCTAD. Curso de solução de disputas em comércio internacional, investimento e propriedade intelectual. Modulo 3.3: apelação. Nova Iorque e Genebra: ONU, 2003.
Até o ano passado, foram feitas um total de 34 submissões em 20 casos na fase de painel, na qual 17 foram aceitas para consideração e, 39 submissões em 15 casos na fase de apelação, na qual foram aceitas 21 para consideração ${ }^{101}$. Porém, após serem aceitas, a forma pela qual são estas são utilizadas continua ambígua, uma vez que nem a sociedade civil nem os próprios membros da OMC são capazes de obter uma visão clara sobre a forma como as submissões amicus podem realmente estar influenciando o resultado de disputas ${ }^{102}$.

Por isso, é arguido que para não ser considerada apenas um aceno simbólico em direção à sociedade civil organizada, o OSC poderia informar que tipo de informação e assistência proveniente da sociedade civil seria do interesse deste ${ }^{103}$.

Outro ponto de destaque, sobre a participação direta de ONGs no sistema de solução de controvérsias, é a demanda por uma abertura das audiências ao público em geral (SANCHEZ BADIN, 2006). A primeira transmissão pública ocorreu nos casos US - Continued Suspension of Obligations e Canada - Continnued Suspension of Obligation, vez que ambas as partes envolvidas nos dois casos requisitaram tal abertura. O painel decidiu a favor da transmissão com base no artigo 12.1 do ESC que prevê que os painéis seguirão os working procedures do Apêndice 3, em conjunto com o artigo 18.2 do ESC que estatui que nenhuma das disposições do ESC deverá impedir uma das partes em controvérsia de publicar suas próprias posições.

O Órgão de Apelação, da mesma forma permitiu a abertura das suas audiências referentes aos casos citados, não obstante o artigo 17.10 do ESC, que exprime que os procedimentos do $\mathrm{OA}$ devem ser confidenciais. Particularmente, diante do artigo 18.2 do ESC, o OA relativizou a confidencialidade em função da vontade dos membros ${ }^{104}$. No entanto, apesar de já

101 MARCEAU, Gabrielle; HURLEY, Mikaella. Transparency and public participation in the WTO: a report card on WTO transparency mechanisms. Trade, Law and Development, v. 4, n. 1, p. 19-44, 2012.

102 MARCEAU, Gabrielle; HURLEY, Mikaella. Transparency and public participation in the WTO: a report card on WTO transparency mechanisms. Trade, Law and Development, v. 4, n. 1, p. 19-44, 2012.

103 MARCEAU, Gabrielle; HURLEY, Mikaella. Transparency and public participation in the WTO: a report card on WTO transparency mechanisms. Trade, Law and Development, v. 4, n. 1, p. 19-44, 2012.

104 Ver: Anexo 2 - Entendimento Relativo às Normas e Procedimentos sobre Solução de Controvérsias. In: BRASIL. 
terem sido transmitidos 19 procedimentos no OSC, entre painel e $\mathrm{OA}$, e de não terem sido concretizadas as preocupações que tais iniciativas transformariam as práticas em um circo midiático, o interesse do público em geral tem sido abaixo das expectativas da OMC, em especial a participação das ONGs, uma vez que a maior parte dos interessados é proveniente da comunidade acadêmica $^{105}$.

Em resumo, é possível afirmar que, apesar de não ser assegurado às representações da sociedade civil direitos de participação ativa, da mesma forma dos países membros, hoje em dia existe um canal aberto de participação por meio da possibilidade de submissão das suas petições e documentos de duas formas: ou anexadas nas petições de algum Estado membro envolvido em uma disputa, ou por meio de submissões avulsas de acordo com os procedimentos estabelecidos pelo OA. Constatou-se, por último, ser possível a transmissão ao público das audiências do $\mathrm{OA}$, desde que os países membros envolvidos na disputa assim permitam.

\section{Considerações finais}

O presente artigo procurou responder se a OMC é accountable, e para tanto procedeu na análise do próprio termo aplicado a uma perspectiva de governança global, no qual se encontram dificuldades de definir quem é o detentor do poder de manter a OMC accountable.

Primeiramente, ao invés de trabalhar na transfusão de modelos ou de tipos gerais de accountability, constatou-se ser mais importante focar na identificação dos três elementos de composição da accountability dentro das instituições de governança global para, consequentemente, responder se estas são accountable, ou promovem a accountability e, assim, trabalhar em cima do aprimoramento de cada uma delas quando necessário.

Ademais, diante das dificuldades de se transpor o conceito de accountability para a governança global, foi identificado neste trabalho dois parâmetros de análise.

Decreto 1.355 de 30 de dezembro de 1994. Promulgo a Ata Final que Incorpora os Resultados da Rodada Uruguai de Negociações Comerciais Multilaterais do GATT. Presidência da República. Brasília, 30, dez. 1994, p. 461.

105 MARCEAU, Gabrielle; HURLEY, Mikaella. Transparency and public participation in the WTO: a report card on WTO transparency mechanisms. Trade, Law and Development, v. 4, n. 1, p. 19-44, 2012.
Em primeiro lugar, constatando-se a não definição da figura do cidadão global, como meio viabilizador de uma democracia, tanto o meio acadêmico, como as próprias OIs têm se valido da figura da sociedade civil como possível substituta, ainda que de forma não perfeitamente concebida, da demos global.

Uma vez que a OMC foi elencada por este trabalho como objeto de pesquisa, analisar a promoção de accountability em seu âmbito, perpassou, primeiramente, na identificação de quem seriam os sujeitos destinatários finais do estabelecimento de normas e padrões regulatórios que emanam da sua atuação. E, em um segundo momento, na verificação dos elementos gerais de composição da accountability, em sua arquitetura institucional.

Partiu-se de duas visões conflitantes: (i) a abordagem intergovernamental, que, restritamente, enxerga apenas os Estados membros como detentores do direito de se utilizarem de mecanismos accountability na OMC, em um plano horizontal, de prestação de contas e aplicação de sanções entre si; (ii) e a abordagem supranacional, que visualiza a atuação da OMC para além de sua abordagem intergovernamental, ao reconhecer na sociedade civil, o destinatário final das ações desta, demandando, portanto uma análise sob uma perspectiva vertical de promoção de elementos de accountability.

No plano horizontal, foi possível verificar a existência e funcionalidade de todos os três elementos de accountability quais sejam: o estabelecimento de padrões, por meio das Conferências Ministeriais, que estipula o consenso como método de adoção de novas regras e padrões; processos de informação por meio de mecanismos de transparência tal como o TPRM, conselhos, comitês e mesmo o site da OMC; e, a aplicação de sanções por meio do braço judiciário da OMC, com base em princípios do devido processo legal, duplo grau de jurisdição e decisões motivadas, que permitem o constrangimento de práticas abusivas no regime multilateral de comércio.

Neste caso, é possível, portanto, concluir que a OMC, se tomada em seu aspecto intergovernamental, representa um caso de promoção de accountability, fazendo com que o direito estabelecido em seu âmbito seja formulado dentro de um processo legítimo, ao menos aos olhos dos seus membros.

Por outro lado, verificou-se no plano vertical, que é possível vislumbrar a presença de alguns princípios fortalecedores da accountability relativa à sociedade civil, 
como forma de políticas promotoras de responsividade, tal como a transparência e participação (não decisória). Contudo, não é possível afirmar seguramente que a OMC promove accountability em relação à sociedade civil. Isto porque: (i) em termos de transparência, a OMC, apresenta duas facetas: uma em termos de difusão de informações (publicidade), que é amplamente aberto ao público, e a outra com relação à participação nos mecanismos de transparência da OMC, como por exemplo o TPRM, que é de participação exclusiva dos países membros; (ii) com relação à participação da sociedade civil nos processos de construção legal e estabelecimento de regras e padrões, disposto nas Conferências Ministeriais, restou exposto que o nível de abertura é bastante tímido, de forma a não permitir que a sociedade civil tenha, concretamente, uma influência nas tomadas de decisões ocorrentes no ínterim das negociações, privilegiando-se, portanto, o modelo member-driven da OMC - neste sentido, a participação da sociedade civil se dá apenas de forma não decisória; (iii) por último, à sociedade civil foi possibilitada um importante canal de participação no processo de enforcement das regras da OMC através do OSC, pois, conforme foi explicado, são permitidas submissões na forma de amicus curiae, tanto na fase de painel como na fase de apelação. Este é um caminho fundamental para tornar as práticas e medidas políticas adotadas pelos membros da OMC accountable às perspectivas da sociedade civil, apesar de, não restar claro a forma pela qual as submissões são aproveitadas, quando apresentadas de forma isolada, ou seja, sem estarem anexadas à petição de uma das partes do litígio.

Ou seja, apesar de serem promovidas importantes ferramentas para um maior engajamento da OMC junto à sociedade civil, tais como a transparência pelo site da OMC, a participação-não decisória nas Conferências Ministeriais e a possibilidade de submissão de petições na forma de amicus curiae no processo de solução de controvérsias, resta ainda fortalecer alguns elementos da accountability, tal como a inclusão da agenda da sociedade civil no plano da tomada de decisões e a possibilidade de esta ter acesso a outros mecanismos de transparência, tal como o TPRB, conselhos e comitês.
Neste plano de análise, é possível se chegar a duas vertentes conclusivas distintas: a primeira indicando que a OMC é uma organização que parcialmente promove a accountability à sociedade civil, justamente por ter aberto a possibilidade de participação desta, naquele que é considerado como os "dentes" dos processos accountability, qual seja, a aplicação de sanções por meio do OSC, permitindo sua influência sobre casos que envolvam, ao seu critério, abusos de poder que desafiem o interesse público, ressaltando-se, no entanto, a necessidade de uma melhor definição procedimental na forma pela qual as submissões isoladas podem ser aproveitadas.

A segunda conclusão, por outro lado, indicando que, de forma geral, a OMC não pode ser reconhecida como uma organização que promove a accountability no plano horizontal, uma vez que esta estabelece apenas determinados mecanismos de responsividade, o que pode gerar questionamentos sobre a legitimidade de suas ações e, consequentemente das suas regras e padrões.

De uma forma ou de outra, não é possível afirmar que a promoção de accountability em relação à sociedade civil se dá em pés de igualdade ao que ocorre em relação aos países membros. A discussão, portanto, gira em torno da gradação a qual se exercem os mecanismos de promoção de accountability, podendo ser entendido que a promoção acontece de uma forma satisfatória, ou que apenas de uma forma circunstancial e marginal.

Por isso, em suma, apesar de ser plausível confirmar a evolução da OMC em termos de fortalecimento de princípios de participação, transparência direcionados à solidificação da promoção de accountability à sociedade civil, permitindo, inclusive, a participação desta no processo de sanção das regras comerciais. Numa perspectiva vertical, não é possível chegar à mesma conclusão que verificada na perspectiva horizontal, qual seja, a de que a OMC promova accountability direcionado à sociedade civil, pois, apesar de promover diversos canais de engajamento com esta, a OMC está presa a sua natureza intergovernamental e member-driven de produção de regras. 


\section{Referências}

BAIMU, Evarist; PANOU, Aristeidis. Responsibility of International Organizations and the World Bank Inspection Panel: parallel tracks unlikely to converge? In: CISSE, Hassane; BRADLOW, Daniel D.; KINGSBURY, Benedict. The World Bank legal review: international financial institutions and global legal governance. Washington: The World Bank, 2012. v. 3.

BATTLE of Seattle. Direção: Stuart Townsend. Hyde Park International, 2007.

BOSSCHE, Van den. The law and policy of the World Trade Organization. Cambridge: Cambridge University Press, 2005.

BR ASIL. Decreto 1.355 de 30 de dezembro de 1994. Promulgo a Ata Final que Incorpora os Resultados da Rodada Uruguai de Negociações Comerciais Multilaterais do GATT. Presidência da República. Brasília, 30 dez. 1994.

CHAISSE, Julien; CHAKRABORTY, Debashis, Implementing WTO rules through negotiations and sanction: the role of Trade Policy Review Mechanism and Dispute Settlement System. University of Pennsylvania Journal of International Economic Law, Philadelphia, v. 28, n. 1, 2007.

CHARNOVITZ, Steve. Transparency and participation in the World Trade Organization. GWU Law School Public Law Research Paper, Washington, n. 142, 2004.

COMISSÃO SOBRE GOVERNANÇA GLOBAL. Nossa comunidade global: o relatório da Comissão Sobre Governança Global. Rio de Janeiro: FGV, 1996.

DUBNICK, Melvin J.; ROMZEK, Barbara. Accountability. In: SHAFRITZ, Jay M. (Org.). The International Encyclopedia of Public Policy and Administration. Westview Press, 1998. v. 1.

FROESE, Marc D. Between surveillance and transparency: trade policy review and north american dispute settlement at the WTO. Canadian University College: Lacombe Paper, p. 1-39, abr. 2012.

GRANT, Ruth W.; KEOHANE, Robert O. Accountability and abuses of power in world politics. American Political Science Review, v. 99, n. 1, fev. 2005.
HALLE, Mark; WOLFE, Robert; BEATON, Christopher. Looking back, looking forward: civil society contributions to WTO accountability. ENTWINED Issue Brief, n. 8, 2011.

KEOHANE, Robert O.. Global governance and democratic accountability. In: HELD, David; KOENIG-ARCHIBUGI, Mathias (Eds.). Taming globalization: frontiers of governance. Cambridge: Polity Press: 2002.

KEOHANE, Robert O.; NYE, Joseph S. Power and interdependence. Boston: Scott, Foresman and Company, 2001.

KINGSBURY, Benedict; KRISCH, Nico; STEWART, Richard B. The emergence of global administrative law. Law and Contemporany Problems, North Carolina, v. 68, n. 3-4, p. 15-62, 2005.

LAFER, Celso. A OMC e a regulamentação do comércio internacional: uma visão brasileira. Porto Alegre: Livraria do Advogado, 1998.

LESTER, Simon. Accountability at the WTO. International Economic Law and Policy Blog. 13 dez. 2009. Disponível em: <http://worldtradelaw.typepad.com/ ielpblog/2009/12/accountability-at-the-w to.html>. Acesso em: 15 jan. 2014.

MARCEAU, Gabrielle; HURLEY, Mikaella. Transparency and public participation in the WTO: a report card on WTO transparency mechanisms. Trade, Law and Development, v. 4, n. 1, p. 19-44, 2012.

MAVROIDIS, Petros C. Amicus curiae briefs before the WTO: much ado about nothing. Jean Monnet Working Paper, v. 2, n. 1, p. 1-18, 2002.

MITCHELL, Andrew D.; SHEARGOLD, Elizabeth. Global governance: the World Trade Organization's contribution. Alberta Law Review, Alberta, v. 46, p. 10611080, jan. 2010.

MULGAN, Richard. One cheer for hierarchly: accountability in disjointed governance. Political Science, v. 55, n. 2 , p.6-18, 2003.

NANZ, Patricia; STEFFEK, Jens. Global governance, participation and the public sphere. In: HELD, David; KOENIG-ARCHIBUGI, Matias. (Ed.). Global 
governance and public accountability. Chichester: WileyBlackwell, 2005. p. 190-211.

PALMER, Alice. Observando de fora: participação da sociedade civil no Sistema de Solução de Controvérsias da OMC. In: BAPTISTA, Luiz Olavo; CELLI JUNIOR, Umberto; YANOVICH, Alan (Org.). 10 anos de OMC: uma análise do Sistema de Solução de Controvérsias e perspectivas. São Paulo: Aduaneiras, 2007.

PAUWELYN, Joost; BERMAN, Ayelet. Emergency action by the WTO director-general: global administrative law and the WTO's initial response to the 2008-09 financial crisis. International Organizations Law Review. v.6, p.499-512, 2009.

PEDRAZA-FARINA, Laura G. Conceptions of civil society in international law-making and implementation: a theoretical framework. Michigan Journal of International Law, Michigan, v. 34, n. 3, p. 101-173, 2013.

PEREZ-ESTEVE, Maria. WTO rules and practices for transparency and engagement with civil society organizations. Staff Working Paper ERSD, Genebra, v. 14, p. 1-28, 2012.

RUBENSTEIN, Jennifer. Accountability in an unequal world. Journal of Politics, v. 69, n. 3, p. 616-632, ago. 2007.

SANCHEZ BADIN, Michelle Ratton. Breves considerações sobre os mecanismos de participação para ONGs na OMC. Revista Internacional de Direitos Humanos, n. 4, ano 3, p. 102-125, 2006.

SCHMIDT, Luis Felipe Flores. A construção da retaliação brasileira no caso algodão: os desafios do pioneirismo. In: BENJAMIN, Daniela Arruda (Org.). O sistema de Solução de Controvérsias da OMC: uma perspectiva brasileira. Brasília: FUNAG, 2013.

SCHOLTE, Jan Aart. Global governance, accountability and civil society. In: SCHOLTE, Jan Aart (Ed.). Building global democracy: civil society and global governance. Cambridge: Cambridge University Press, 2011.

SILVA, Luiz Fernando Martins da. Amicus curiae: direito e ação afirmativa. Revista Jurídica, Brasília, v. 7, n. 76, p. 70-78, 2006.
SMYTHE, Elizabeth; SMITH, Peter J. Legitimacy, transparency, and information technology: the World Trade Organization in an era of contentious trade politics. Global governance: a review of multilateralism and international organizations, v. 12, n. 1, p. 31-53, jan. 2006.

STEWART, Richard B.; SANCHEZ BADIN, Michelle Ratton. The World Trade Organization and global administrative law. NYU School of Law Public Law Research Paper, Nova Iorque, n. 09-71, p. 1-31, 2009.

UNCTAD. Curso de solução de disputas em comércio internacional, investimento e propriedade intelectual. Modulo 3.3: Apelação. Nova Iorque e Genebra: ONU, 2003.

UNITED NATIONS CONFERENCE ON TRADE AND EMPLOYMENT. Final act and related documents. Interim Comission for the International Trade Organization: Lake Success, abr. 1948.

VANGRASSTEK, Craig. The history and the future of the World Trade Organization. Genebra: WTO Publications, 2013.

WILLIAMS, Mark. Civil society and the WTO: contesting accountability. In: SCHOLTE, Jan Aart (Ed.). Building global democracy: civil society and global governance. Cambridge: Cambridge University Press, 2011.

WOLFE, Robert. Who is accountable at the World Trade Organization?: anatomy of a trilemma within a dilemma. Kingston, p. 1-19, (no prelo).

WTO. $W T / L / 162$ : Guidelines for arrangements on relations with Non-Governmental Organizations. Genebra, 23 jul. 1996. Disponível em: <http://www. wto.org/english/forums_e/ngo_e/guide_e.htm>. Acesso em: 20 fev. 2014.

WTO. WT/DS58/AB/R: United States - Import Prohibition of Certain Shrimp and Shrimp Products. Genebra, 12 out. 1998.

WTO. $W T / D S 138 / A B / R$ : United States - Imposition of Countervailing Duties on Certain Hot-Rolled Lead and Bismuth Carbon Steel Products Originating in the United Kingdom. Genebra, 10 mai. 2000. 
WTO. $W T / G C / M / 60$ : minutes of meeting Held in the Centre William Rappard on 22 November 2000. Genebra, 23 jan. 2001.

WTO. WT/DS135/AB/R: European Communities Measures Affecting Asbestos and Products Containing Asbestos. Genebra, 12 mar. 2001.

WTO. The future of the WTO: addressing institutional challenges in the new millennium. Genebra: WTO Publications, 2004.

WTO. Understanding the WTO. Genebra: WTO Publications, 2008.
WTO. The WTO agreements series: sanitary and phytosanitary measures. Genebra: WTO Publications, 2010. Disponível em: <http://wto.org/english/res_e/booksp_e/ agrmntseries4_sps_e.pdf>. Acesso em: 12 dez. 2014.

WTO. Trade policy reviews: brief introduction. Genebra. Disponível em: <http://wto.org/english/tratop_e/ tpr_e/tp_int_e.htm>. Acesso em: 14 fev. 2014a.

WTO. Trade monitoring. Genebra. Disponível em: <http://www.wto.org/english/tratop_e/tpr_e/trade_ monitoring_e.htm>. Acesso em: 02 mar. 2014b. 
Para publicar na Revista de Direito Internacional, acesse o endereço eletrônico www.rdi.uniceub.br ou www.brazilianjournal.org.

Observe as normas de publicação, para facilitar e agilizar o trabalho de edição. 